\title{
ADP secreted by dying melanoma cells mediates chemotaxis and chemokine secretion of macrophages via the purinergic receptor $\mathrm{P} 2 \mathrm{Y} 12$
}

Loreen Kloss', Claudia Dollt ${ }^{1}$, Kai Schledzewski ${ }^{1}$, Andreas Krewer ${ }^{1}$, Susanne Melchers ${ }^{1}$, Calin Manta', Carsten Sticht ${ }^{2}$, Carolina de la Torre ${ }^{2}$, Jochen Utikal ${ }^{1,3}$, Viktor Umansky ${ }^{1,3}$ and Astrid Schmieder ${ }^{1}$

\begin{abstract}
Melanoma immunotherapy is still not satisfactory due to immunosuppressive cell populations within the tumor stroma. Targeting tumor-associated macrophages (TAM) can help to restore an anti-tumor immunity. Previously, we could show that classical TAM markers expressed in vivo need a 7 day M-CSF/dexamethasone/IL-4 (MDI) stimulation for their induction in peripheral blood monocytes ( $\mathrm{pBM}$ ) in vitro. To identify possible novel therapeutic targets on TAM, gene expression analysis of MDI-treated pBM was performed. This identified up-regulation of the purinergic G-protein coupled receptor P2Y12, the therapeutic target of the clinically approved anti-thrombotic drugs cangrelor, clopidogrel, ticagrelor, and prasugrel. We generated a peptide antibody and validated its specificity using transgenic P2Y12 ${ }^{+}$U937 cells. With the help of this antibody, P2Y12 expression was confirmed on $\mathrm{CD}_{6} 8^{+} \mathrm{CD} 163^{+} \mathrm{TAM}$ of melanoma in situ. Functional analysis revealed that treatment of transgenic P2Y12 ${ }^{+}$U937 cells with the receptor agonist 2-MeSADP induced ERK1/2 and Akt phosphorylation and increased the secretion of the chemokines CXCL2, CXCL7, and CXCL8. These effects could be abolished with the P2Y12 antagonist PSB0739 or with Akt and ERK inhibitors. In addition, $\mathrm{P}_{2} \mathrm{Y}_{12}{ }^{+}$macrophages migrated towards the ADP-rich culture medium of puromycin-treated dying B16F1 melanoma cells. Cangrelor treatment blocked migration. Taken together, our results indicate that P2Y12 is an important chemotaxis receptor, which triggers migration of macrophages towards nucleotide-rich, necrotic tumor areas, and modulates the inflammatory environment upon ADP binding.
\end{abstract}

\section{Introduction}

Immunosuppressive cells such as tumor-associated macrophages (TAM) are prominent components of the tumor microenvironment ${ }^{1}$. A high infiltration of TAM correlates with poor outcome in different tumor entities including melanoma ${ }^{2}$.

In general, macrophages are highly plastic cells that quickly adapt to different environments ${ }^{3}$. Based on

\footnotetext{
Correspondence: Astrid Schmieder (Astrid.Schmieder@umm.de)

1 Department of Dermatology, Venereology and Allergology, University Medical Center and Medical Faculty Mannheim, University of Heidelberg, Mannheim, Germany

${ }^{2}$ Center for Medical Research, Medical Faculty Mannheim, University of Heidelberg, Mannheim, Germany

Full list of author information is available at the end of the article.

Edited by J.-E. Ricci
}

in vitro models, macrophages have been classified in proinflammatory M1-like and anti-inflammatory M2-like macrophages ${ }^{4}$. While at tumor initiation macrophages predominantly exhibit a M1 phenotype, the tumor microenvironment strongly polarizes macrophages to a M2 phenotype during tumor progression ${ }^{5}$. These TAM promote tumor growth, invasion and angiogenesis by secreting growth factors (e.g. vascular endothelial growth factor) and matrix metalloproteinases. Furthermore, TAM support immune evasion by the expression of various anti-inflammatory mediators such as interleukin 10 (IL-10), transforming growth factor $\beta$ (TGF- $\beta$ ) and arginase $-1^{6}$. By secreting chemokines, they can attract other immunosuppressive cells such as myeloid-derived suppressor cells and regulatory $\mathrm{T}$-cells to the tumor

\section{(c) The Author(s) 2019}

(c) (i) Open Access This article is licensed under a Creative Commons Attribution 4.0 International License, which permits use, sharing, adaptation, distribution and reproduction c. in any medium or format, as long as you give appropriate credit to the original author(s) and the source, provide a link to the Creative Commons license, and indicate if changes were made. The images or other third party material in this article are included in the article's Creative Commons license, unless indicated otherwise in a credit line to the material. If material is not included in the article's Creative Commons license and your intended use is not permitted by statutory regulation or exceeds the permitted use, you will need to obtain permission directly from the copyright holder. To view a copy of this license, visit http://creativecommons.org/licenses/by/4.0/. 
microenvironment ${ }^{7,8}$. Based on the described pro-tumoral and immunosuppressive abilities of M2-like macrophages they classify as promising therapeutic targets especially when combined with immune checkpoint inhibitors?. Thus, it is crucial to identify and characterize novel TAM markers that can be targeted therapeutically to improve an anti-melanoma immune response.

P2Y12 is a purinergic, G-protein coupled receptor that is activated by adenosine diphosphate (ADP). Since P2Y12 couples to $G_{i}$ proteins, the $G \alpha$ subunit inhibits adenylyl cyclase while the GßY subunit activates PI3K/Akt signaling $^{10}$. P2Y12 is expressed on platelets, triggering platelet activation and aggregation. Thus, clinically approved P2Y12 antagonists such as clopidogrel, ticagrelor, cangrelor, and prasugrel are widely used to treat thrombotic disorders and are commonly given in combination with $\operatorname{aspirin}^{11}$.

Besides platelets, P2Y12 is expressed on microglial cells mediating nucleotide sensing and microglial chemotaxis following nerve injury ${ }^{12}$. Recently, P2Y12 expression was also detected on several other immune cells including dendritic cells, mast cells, and eosinophils ${ }^{13-15}$.

Concerning neoplastic disease, a meta-analysis by the Food and Drug Administration (FDA) in 2014 showed no increased risk in cancer deaths under long-term clopidogrel plus aspirin treatment compared to short-term clopidogrel plus aspirin or aspirin alone ${ }^{16}$. However, some randomized controlled trials reported higher cancer risk especially with ticagrelor and prasugrel ${ }^{16-18}$. Whether these effects derive from the inhibition of platelet aggregation or the blocked binding of ADP to P2Y12 expressed on other hematopoietic cells has not been analyzed yet.

Here we show that P2Y12 is expressed on $\mathrm{CD}_{163^{+}}$ TAM of human melanoma in situ. In transgenic P2Y12 ${ }^{+}$ U937 cells, ADP induces the secretion of several chemokines among them CXCL2, CXCL7, and CXCL8. Furthermore, we demonstrate that ADP acts as a find-me signal as nucleotides released by dying tumor cells significantly promote the migration of $\mathrm{P} 2 \mathrm{Y}_{1} 2^{+}$macrophages. Our results indicate that $\mathrm{P} 2 \mathrm{Y}_{2} 2^{+}$macrophages are attracted to nucleotide-rich tumor environments where they modulate the inflammatory milieu upon ADP binding.

\section{Results}

Gene expression analysis revealed up-regulation of P2Y12 in $\mathrm{pBM}_{(\mathrm{MDI})}$

In the past our group showed that most of the typical human tumor-associated macrophage (TAM) markers such as Stabilin-1, CD163 and Lyve-1 need the combined stimulation with macrophage colony-stimulating factor (M-CSF), dexamethasone and interleukin 4 (IL-4) (MDI) for their induction in human peripheral blood monocytes (pBM) in vitro. To identify possible new therapeutic targets on TAM, we performed gene expression analysis of $\mathrm{pBM}_{(\mathrm{MDI})}$ and compared it to M-CSF-stimulated $\mathrm{pBM}$ $\left(\mathrm{pBM}_{(\mathrm{M}-\mathrm{CSF})}\right)$. One of the highest up-regulated genes in $\mathrm{pBM}_{(\mathrm{MDI})}$ was the purinergic receptor P2Y12 (Table 1). Interestingly, P2Y14, which is a member of the P2Y12-like group, was also strongly up-regulated in $\mathrm{pBM}_{(\mathrm{MDI})}$ (Table 1). In contrast to P2Y12, this purinergic receptor binds UDP-sugars and plays a role in recruitment of macrophages to the liver ${ }^{19}$. Since P2Y12 is the therapeutic target of already clinically approved anti-thrombotic drugs such as clopidogrel, ticagrelor, cangrelor, and prasugrel and such drugs are not available for P2Y14, we focused on the molecular and functional characterization of P2Y12.

\section{P2Y12 protein expression can be detected in $\mathrm{pBM}_{(\mathrm{MDI})}$}

To verify protein expression of P2Y12, we generated a rabbit polyclonal anti-hsP2Y12 peptide antibody against the C-terminal amino acid sequence SQDNRKKEQDGGDPNEETPM which is uniquely expressed by P2Y12 and not by other members of the P2Y12-like group (Fig. 1a). Specificity was validated using transgenic P2Y12 ${ }^{+}$U937 cells (Fig. 1b). Immunocytochemical stainings (ICC) and western blot analysis detected P2Y12 exclusively in transgenic P2Y12 ${ }^{+}$ U937 cells. Pre-incubation of anti-P2Y12 with the blocking peptide abrogated binding of the antibody to P2Y12 in ICC and western blot analysis (Fig. 1c, d). In platelets our antibody identified a specific protein band at $40 \mathrm{kDa}$, while in transgenic U937 cells as well as $\mathrm{pBM}_{(\mathrm{MDI})}$ the same antibody detected a specific band at $\sim 60 \mathrm{kDa}$. Both bands have a higher molecular weight than expected for the P2Y12 amino acid sequence (342 amino acids). Since P2Y12 has two described $\mathrm{N}$-linked glycosylation sites (position 6 and 13) we treated the protein lysates with Peptide $N$-Glycosidase F (PNGase F) which led to specific protein bands at $\sim 37 \mathrm{kDa}$ in all three cell types. This corresponds to the actual P2Y12 amino acid length. In addition, immunohistochemical stainings of glioblastoma sections revealed P2Y12 expression in $\mathrm{CD}^{+} 8^{+}$microglial cells (Fig. 1e) which is in line with already published data by Mildner et al. ${ }^{20}$.

After the specificity of the antibody was proofed, we used it to correlate protein expression with mRNA levels in pBM. As seen by microarray analysis, MDI strongly induced P2Y12 mRNA which was accompanied by increased protein expression (Fig. 2a, b). P2Y12 induction was time-dependent reaching the highest mRNA levels after five days of stimulation whereas protein expression was even stronger after seven days of MDI treatment (Fig. 2c, d). Stimulations with IL-4 or dexamethasone alone as well as with IL-10, TGF- $\beta$, interferon $\gamma$ (INF- $\gamma$ ), tumor necrosis factor $\alpha$ (TNF- $\alpha$ ), IFN- $\gamma+$ TNF- $\alpha$ and lipopolysaccharide (LPS) failed to induce P2Y12 expression in pBM (Fig. 2e). Treatment of the cells with the glucocorticoid receptor antagonist mifepristone significantly abrogated the MDI-induced P2Y12 expression (Fig. 2f). 
Table 1 Gene expression analysis of $\mathrm{pBM}_{(\mathrm{MDI})}$ versus pBM $_{\text {(M-CSF) }}$

\begin{tabular}{|c|c|c|}
\hline Gene symbol & Gene name & Fold change \\
\hline P2RY12 & $\begin{array}{l}\text { Purinergic receptor P2Y, G-protein } \\
\text { coupled, } 12\end{array}$ & 44.4 \\
\hline P2RY14 & $\begin{array}{l}\text { Purinergic receptor P2Y, G-protein } \\
\text { coupled, } 14\end{array}$ & 40.8 \\
\hline CCL13 & Chemokine (C-C motif) ligand 13 & 33.9 \\
\hline F13A1 & Coagulation factor XIII, A1 polypeptide & 31.6 \\
\hline FCER2 & $\begin{array}{l}\text { Fc fragment of IgE, low affinity II, } \\
\text { receptor for (CD23) }\end{array}$ & 30.8 \\
\hline PDK4 & $\begin{array}{l}\text { Pyruvate dehydrogenase kinase, } \\
\text { isozyme } 4\end{array}$ & 28.8 \\
\hline GLDN & Gliomedin & 22.9 \\
\hline ADORA3 & Adenosine $\mathrm{A} 3$ receptor & 21.3 \\
\hline CD200R1 & CD200 receptor 1 & 20.1 \\
\hline LYVE1 & $\begin{array}{l}\text { Lymphatic vessel endothelial } \\
\text { hyaluronan receptor } 1\end{array}$ & 15.0 \\
\hline DAAM2 & $\begin{array}{l}\text { Disheveled associated activator of } \\
\text { morphogenesis } 2\end{array}$ & 14.5 \\
\hline EPS8 & $\begin{array}{l}\text { Epidermal growth factor receptor } \\
\text { pathway substrate } 8\end{array}$ & 12.1 \\
\hline SESN1 & Sestrin 1 & 12.0 \\
\hline SEP3 & Septin 3 & 11.7 \\
\hline MAOA & Monoamine oxidase A & 11.3 \\
\hline CD209 & CD209 molecule & 11.2 \\
\hline FGL2 & Fibrinogen-like 2 & 10.2 \\
\hline SHMT1 & $\begin{array}{l}\text { Serine hydroxymethyltransferase } 1 \\
\text { (soluble) }\end{array}$ & 9.5 \\
\hline MTSS1 & Metastasis suppressor 1 & 9.1 \\
\hline SOCS1 & Suppressor of cytokine signaling 1 & 9.1 \\
\hline
\end{tabular}

$\mathrm{CD}_{14}{ }^{+} \mathrm{pBM}$ were isolated from the blood of three healthy donors and stimulated for 7 days with M-CSF or MDI. Microarray analysis was performed and the gene fold change of MDI versus M-CSF-treated pBM was calculated. Only the 20 highest up-regulated genes are shown

Our results indicate that only the combined treatment with MDI induces P2Y12 expression in pBM in vitro. This up-regulation can efficiently be inhibited by the glucocorticoid receptor antagonist mifepristone.

P2Y12 is expressed on human CD163 ${ }^{+}$TAM of melanoma

Next, we stained human melanoma sections and located P2Y12 on a subset of $\mathrm{CD}^{+} 8^{+}$macrophages in human primary as well as skin metastatic lesions of melanoma (Fig. 3a). In situ hybridization confirmed this finding on mRNA level (Fig. 3b). Sequential stainings identified
P2Y12 on a subpopulation of $\mathrm{CD}^{+} 8^{+}$TAM which also express CD163 (Fig. 3c). The existence of $\mathrm{P} 2 \mathrm{Y}_{2} 2^{+}$ $\mathrm{CD}_{163}{ }^{+}$TAM was verified by immunofluorescence (Fig. 3d).

\section{ADP induces the expression and secretion of chemokines in transgenic P2Y12 ${ }^{+}$U937 cells}

To identify genes that are up-regulated by ADP in P2Y12 ${ }^{+}$U937 cells, we performed microarray analysis. Instead of ADP we used 2-Methylthioadenosine diphosphate (2-MeSADP) - a stable non-hydrolysable analog of ADP - to avoid cleavage of ADP by ectonucleotidases, which are also known to be expressed by macrophages. Among the highest up-regulated genes in 2-MeSADPtreated P2Y12 ${ }^{+}$U937 cells (P2Y12 ADP) compared to untreated P2Y12 ${ }^{+}$U937 cells (P2Y12 CTRL) were several cytokines [IL-1ß, TGF- 33 , TNF super family member (TNFSF)15, TNFSF8], chemokines (CXCL8, CXCL7, CCL3L3, CXCL3, CCL20, and CXCL2) and growth factors [heparin binding epidermal growth factor (HB-EGF)] (Fig. 4a and Supplementary Table 1). We confirmed upregulation of the chemokines CXCL8, CXCL7 as well as CXCL2 in P2Y12 ADP by qRT-PCR (Fig. 4b). Elevated concentrations of these chemokines were detected in the supernatant of P2Y12 ADP by enzyme-linked immunosorbent assay (ELISA) (Fig. 4c). Among those chemokines, CXCL7 was the protein with the highest concentration in the supernatant of P2Y12 ADP $(511 \mathrm{pg} / \mathrm{mL})$, followed by CXCL8 $(454 \mathrm{pg} / \mathrm{mL})$ and CXCL2 $(14 \mathrm{pg} / \mathrm{mL})$. When $\mathrm{P} \mathrm{Y}_{2}{ }^{+}$U937 cells were pretreated with the P2Y12specific antagonist PSB0739, chemokine secretion was significantly reduced (Fig. 4d). We did not find increased chemokine secretion of CXCL2, CXCL8, and CXCL7 in 2MeSADP-treated $\mathrm{pBM}_{(\mathrm{MDI})}$ though, 2-MeSADP upregulated similar genes in $\mathrm{P}_{2} \mathrm{Y}_{2}{ }^{+} \mathrm{pBM}_{(\mathrm{MDI})}$ as found by microarray analysis in 2-MeSADP-treated $\mathrm{P} 2 \mathrm{Y}^{+} 2^{+} \mathrm{U} 937$ cells (data not shown).

\section{Blockade of ADP-induced ERK and Akt signaling inhibits chemokine secretion in $\mathrm{P}_{2} \mathrm{Y}_{12}^{+}$U937 cells}

In order to identify signaling pathways responsible for the ADP-dependent chemokine secretion in $\mathrm{P} 2 \mathrm{Y}_{12}{ }^{+} \mathrm{U} 937$ cells, we performed western blot analysis. ERK1/2 phosphorylation (after $5 \mathrm{~min}$ ) as well as AKT phosphorylation (after $5 \mathrm{~min}$ and $30 \mathrm{~min}$ ) was detected after treatment of $\mathrm{P} \mathrm{Y}_{2}{ }^{+}$U937 cells with 2-MeSADP. These signaling pathways were only weakly induced in 2-MeSADP-treated EV cells (Fig. 5a). Furthermore, 2-MeSADP induced the expression of the transcription factor subunits FOSL1 and JUN in P2Y12 ${ }^{+}$U937 cells (Fig. 5b). Pretreatment of these cells with an Akt inhibitor prior to 2-MeSADP stimulation significantly reduced the expression of FOSL1 and JUN while pre-treatment with an ERK inhibitor only slightly decreased the expression of both transcription factor 
a

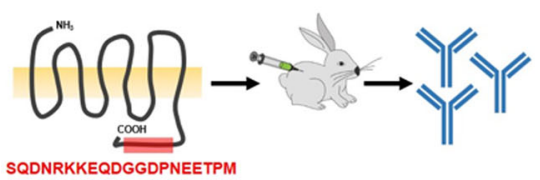

b

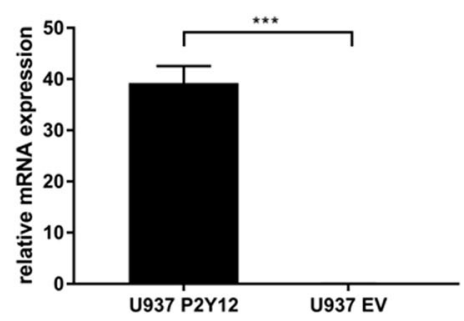

d

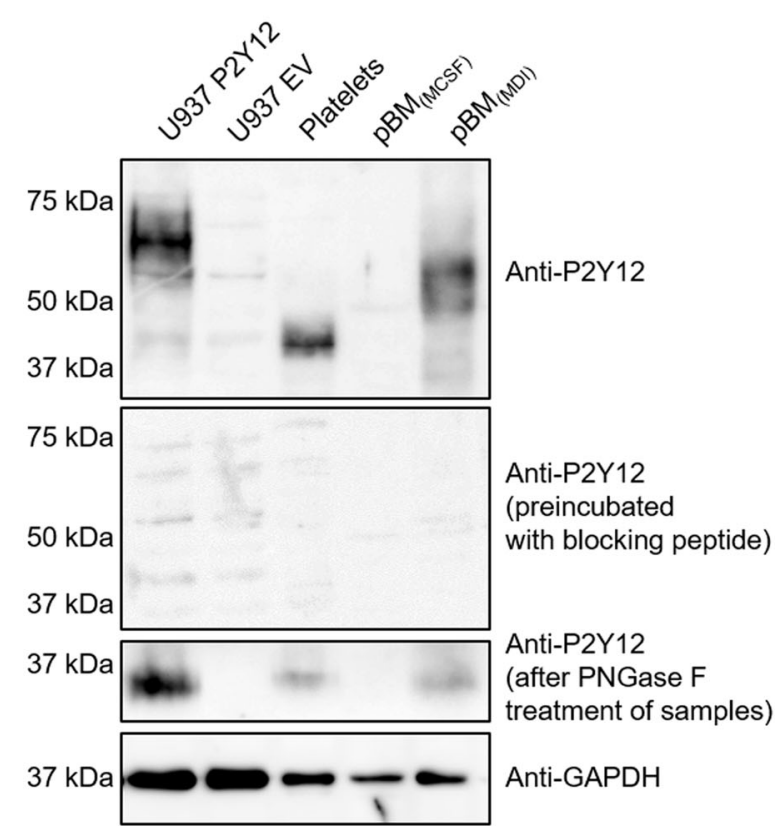

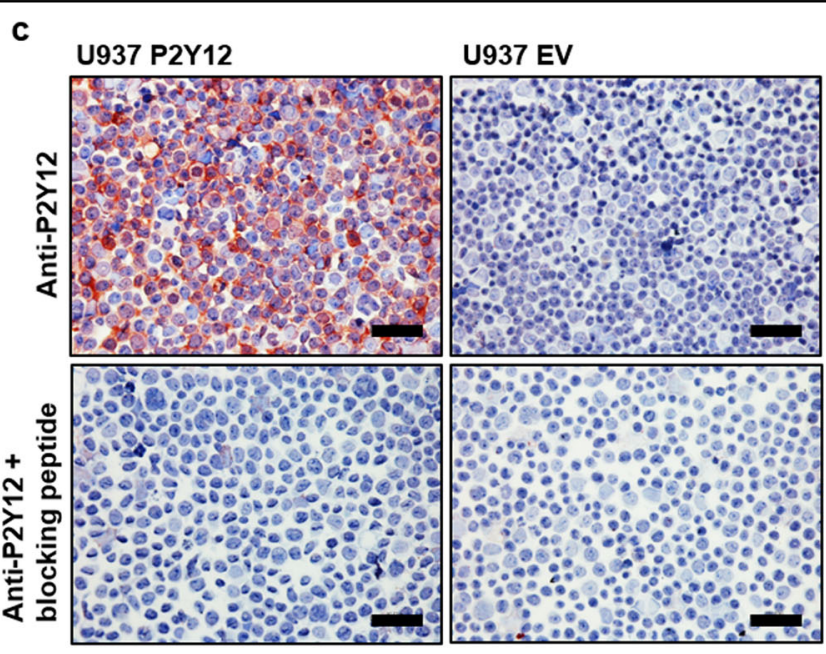

e

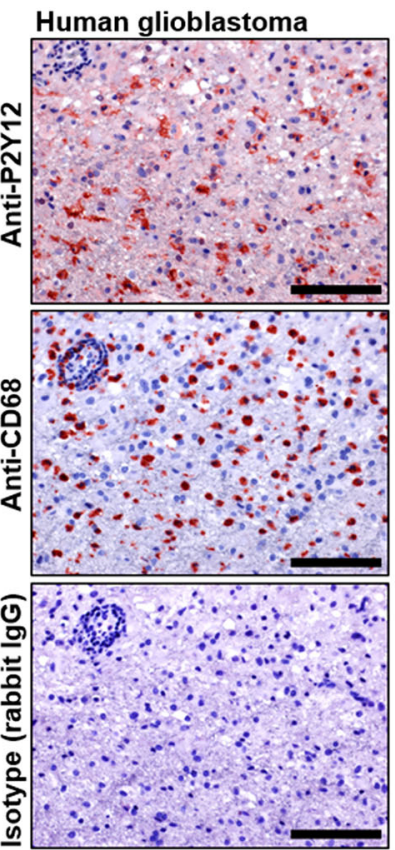

Fig. 1 Generation and validation of a specific rabbit anti-hsP2Y12 peptide antibody. a A rabbit polyclonal anti-hsP2Y12 antibody targeting the intracellular C-terminal sequence SQDNRKKEQDGGDPNEETPM was generated. b P2Y12 mRNA expression in transgenic U937 cells was assessed by qRT-PCR. Gene expression was normalized to B-actin $(n=3)$. c P2Y12 protein expression in transgenic U937 cells was assessed by

immunocytochemistry using the self-generated rabbit anti-hsP2Y12 antibody. As a control, the antibody was preincubated with the blocking peptide (SQDNRKKEQDGGDPNEETPM) ( $n=3$, one exemplary experiment is shown). Scale bar $=100 \mu \mathrm{m}$. d P2Y12 protein expression in transgenic U937 cells, platelets, and pBM was assessed by Western blot analysis using the self-generated rabbit anti-hsP2Y12 antibody. As a control, the antibody was preincubated with the blocking peptide (SQDNRKKEQDGGDPNEETPM). To analyze differences in the N-glycosylation-status of P2Y12 between cells, protein lysates were treated with PNGase F. Anti-GAPDH antibody was used as loading control. e Immunohistochemical staining of human glioblastoma sections using anti-hsP2Y12, anti-hsCD68 and isotype control of the anti-hsP2Y12 antibody (rabbit lgG) $(n=3)$. Scale bar $=100 \mu \mathrm{m}$. For all stainings one representative picture is shown

subunits (Fig. 5c). To verify whether 2-MeSADP induces chemokine expression via Akt and/or ERK signaling, we pretreated transgenic P2Y12 ${ }^{+}$U937 cells with Akt and ERK inhibitors and detected reduced secretion of CXCL2,
CXCL7 as well as CXCL8 upon 2-MeSADP treatment (Fig. 5d). The strongest inhibition was achieved upon simultaneous blockade of Akt and ERK signaling pathways (Fig. 5d). 
a

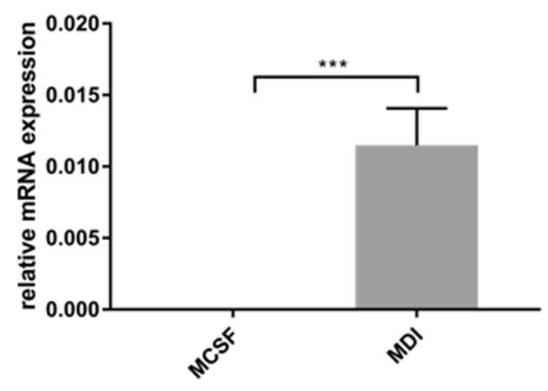

C

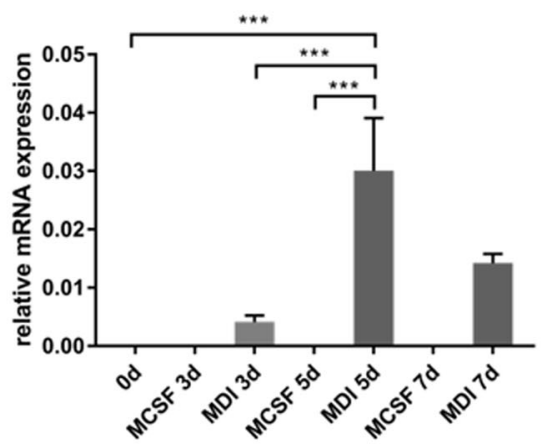

e

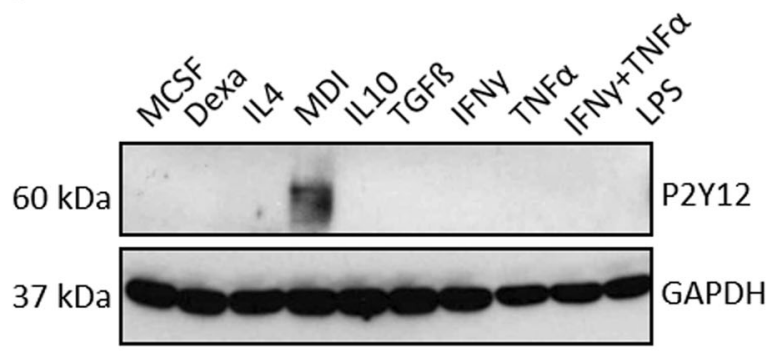

b

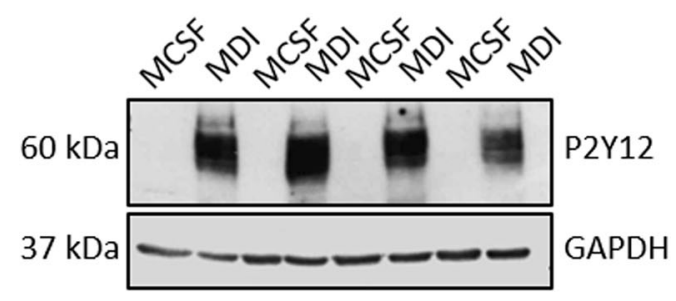

d

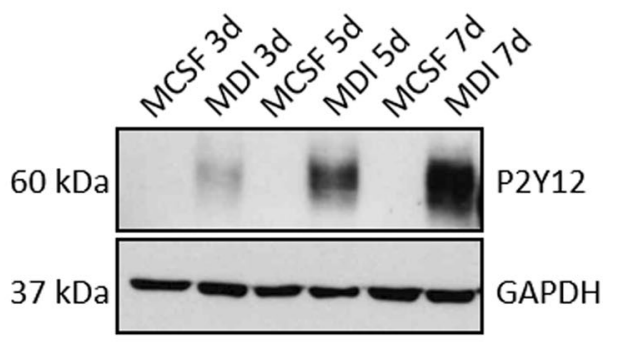

$\mathbf{f}$

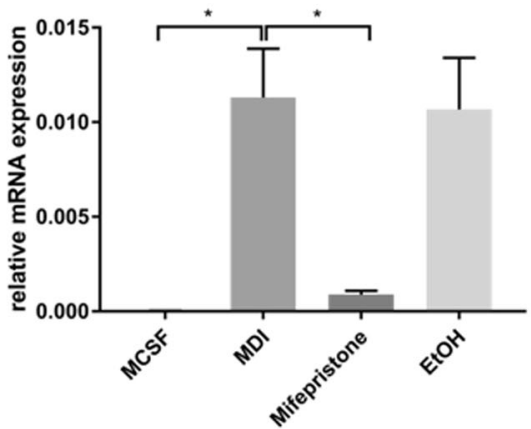

Fig. 2 P2Y12 can only be induced by the combined treatment of pBM with MDI. $\mathbf{a}, \mathbf{b}$ P2Y12 expression in pBM treated with MDI or M-CSF for 7 days was analyzed by qRT-PCR $(\mathbf{a})(n=11)$ and Western blot analysis $(\mathbf{b})(n=3)$. $\mathbf{c}$, $\mathbf{d}$ Time-dependent induction of P2Y12 expression after 3,5 , and 7 days was analyzed by qRT-PCR (c) $(n=6)$ and western blot analysis $(\mathbf{d})(n=3)$. e P2Y12 expression was assessed after treatment of pBM with M-CSF alone or M-CSF plus the indicated pro-and anti-inflammatory cytokines for 7 days by western blot analysis $(n=3)$. $\mathbf{f}$ P2Y12 induction in pBM treated with M-CSF, MDI, or MDI plus mifepristone for 7 days was assessed by qRT-PCR. Cells treated with equivalent concentration of ethanol (EtOH) were used as control $(n=4)$. For all experiments one representative western blot is depicted. Gene expression was normalized to B-actin. Data is expressed as mean \pm SEM

\section{ADP promotes migration of $\mathrm{P}_{2} \mathrm{Y}_{12}^{+}$macrophages}

Since it is known that P2Y12 triggers migration of microglia cells to the site of inflammation, we investigated whether ADP might also act as a chemoattractant for other $\mathrm{P} 2 \mathrm{Y}_{12}{ }^{+}$macrophages. We set up a transwell migration assay with M-CSF and MDI-treated pBM. 2MeSADP promoted the migration of $\mathrm{P}^{2} \mathrm{Y}^{+} 2^{+} \mathrm{pBM}_{(\mathrm{MDI})}$ whereas it had no significant effect on the migration of $\mathrm{pBM}_{(\mathrm{M}-\mathrm{CSF})}$ lacking P2Y12 expression (Fig. 6a, b). The clinically approved P2Y12 antagonist cangrelor inhibited the migration of $\mathrm{P}^{2} \mathrm{Y}^{+} 2^{+} \mathrm{pBM}_{(\mathrm{MDI})}$ towards 2-MeSADP (Fig. 6c, d). To provide further proof that $\mathrm{P} 2 \mathrm{Y} 12$ is responsible for the increased migration of macrophages towards ADP, we used Raw 264.7 cells, an adherent murine macrophage-like cell line, and stably overexpressed P2Y12 in these cells. Like for $\mathrm{P}^{\mathrm{Y} 12^{+}} \mathrm{pBM}_{(\mathrm{MDI})}$, 2-MeSADP also acted as a chemoattractant for $\mathrm{P}^{2} \mathrm{Y}^{+}$Raw 264.7 cells (Fig. 6e, f), while it was no chemoattractant for EV Raw 264.7 cells. 


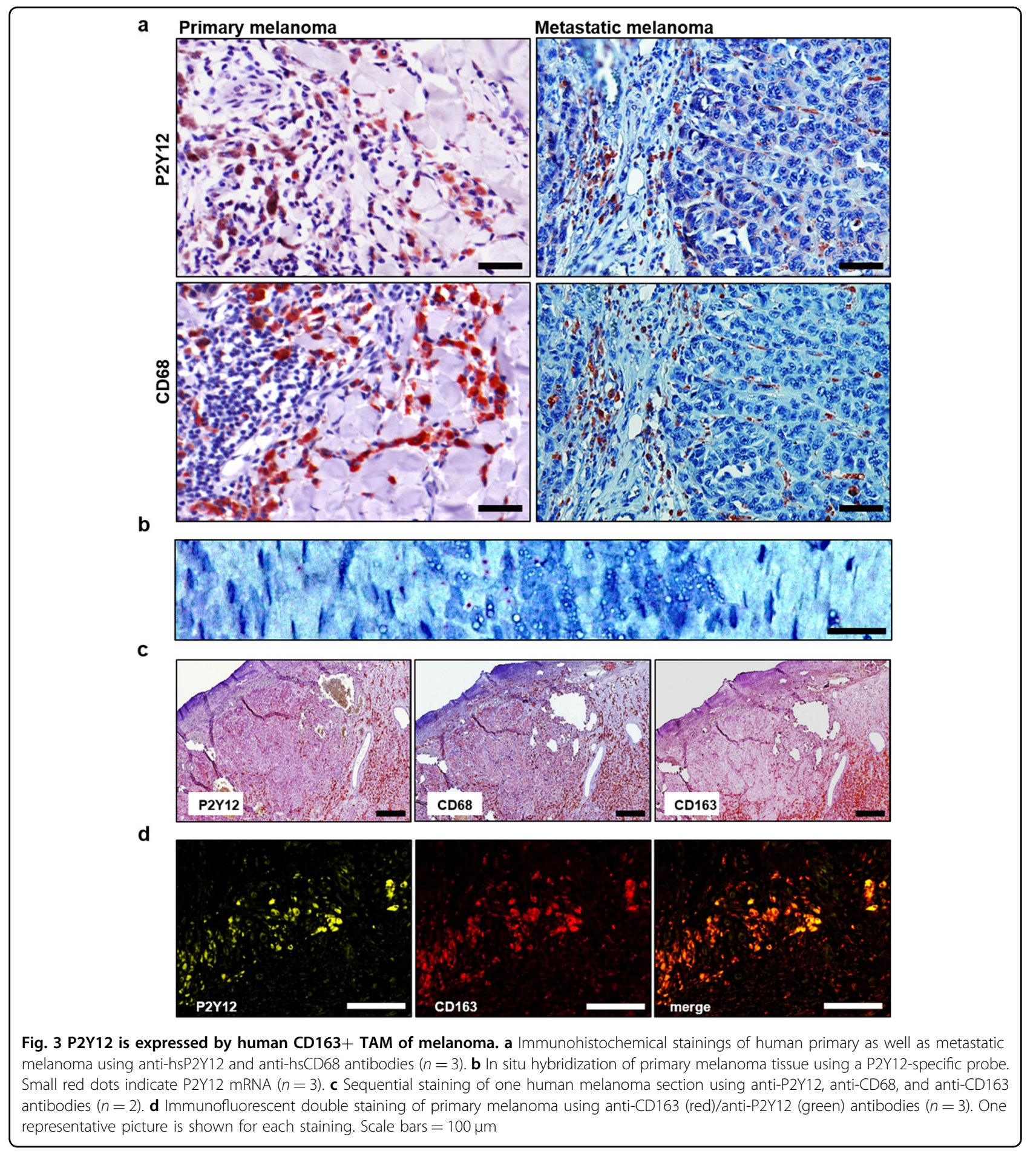

ADP released by dying tumor cells promotes the migration of $\mathrm{P}_{2} \mathrm{Y}_{12}^{+}$Raw 264.7 cells

To provide evidence that nucleotides released by dying tumor cells act as a find-me signal for $\mathrm{P} 2 \mathrm{Y}_{1} 2^{+}$macrophages, we set up a transwell co-culture experiment with P2Y12 ${ }^{+}$Raw 264.7 cells and puromycin-pretreated B16F1 melanoma cells. Since the transgenic Raw 264.7 cells contain a puromycin resistance cassette, their viability was not affected by the treatment. Puromycin-pretreated B16F1 cells in the lower transwell chamber significantly promoted the migration of $\mathrm{P} 2 \mathrm{Y}_{12}{ }^{+}$cells, while untreated B16F1 cells as well as medium alone did not (Fig. 7a, b). EV Raw 264.7 cells were only slightly attracted by dying puromycin-pretreated B16F1 cells (Fig. 7a). To test 
a

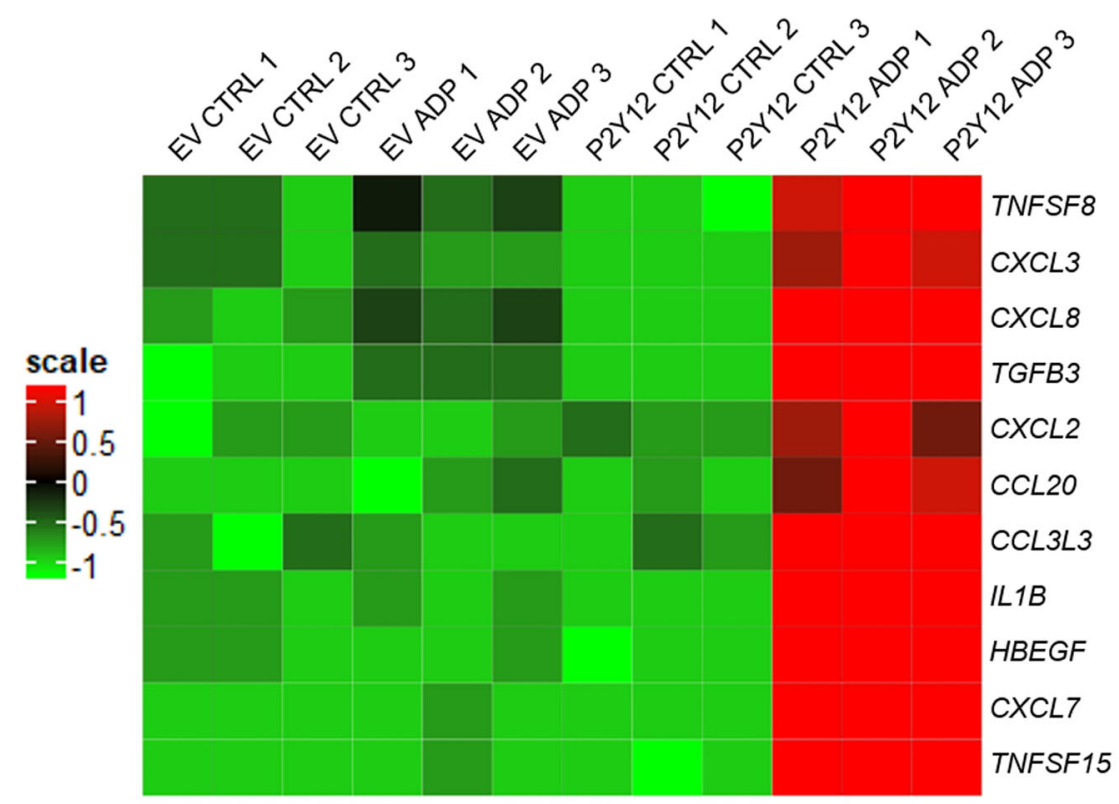

b

U937 P2Y12 U937 EV

CXCL8

CXCL7
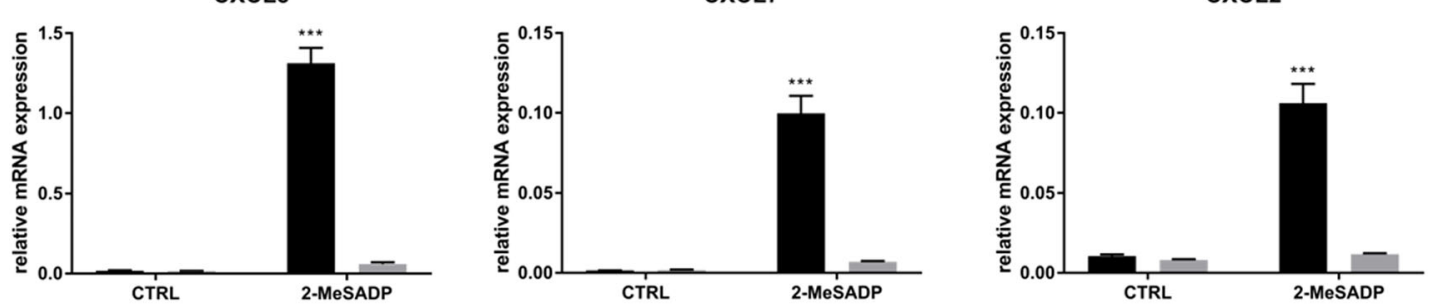

C

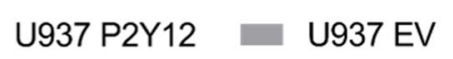

CXCL8

CXCL7
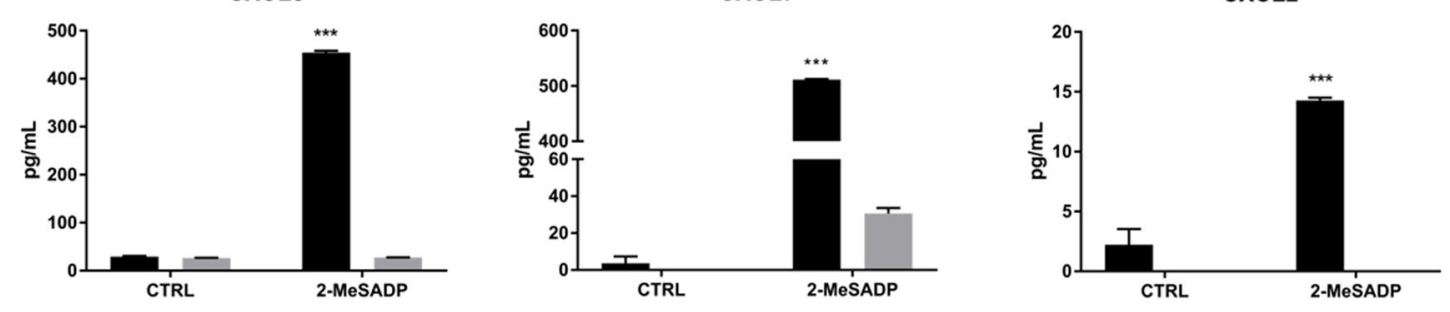

d
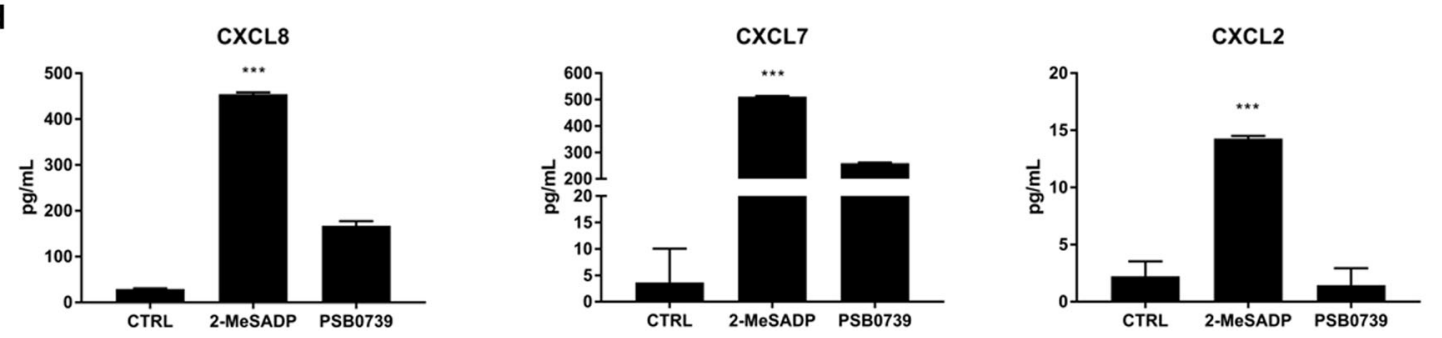

Fig. 4 (See legend on next page.) 
(see figure on previous page)

Fig. 4 ADP induces chemokine secretion in transgenic P2Y12 ${ }^{+}$U937 cells which can be inhibited with the specific P2Y12 antagonist PSB0739. a Gene expression analysis of transgenic U937 cells stimulated with $50 \mathrm{nM}$ 2-MeSADP for $4 \mathrm{~h}$. Heatmap depicts up-regulated cytokines, chemokines, and growth factors in 2-MeSADP-treated P2Y12+ U937 cells (P2Y12 ADP) compared to untreated P2Y12 ${ }^{+}$cells (P2Y12 CTRL), 2-MeSADPtreated EV cells (EV ADP), and untreated EV cells (EV CTRL) $(n=3)$. b Transgenic U937 cells were treated with $50 \mathrm{nM} 2-\mathrm{MeSADP}$ for $4 \mathrm{~h}$ and gene expression of the indicated chemokines was assessed by qRT-PCR. Gene expression was normalized to GAPDH $(n=4)$. c Chemokine concentrations in the cell supernatants of transgenic U937 cells were assessed by ELISA $(n=4)$. $\mathbf{d}$ P2Y12 $2^{+}$U937 cells were pre-treated with $10 \mu \mathrm{M}$ PSB0739 prior to stimulation with $50 \mathrm{nM}$ 2-MeSADP for $24 \mathrm{~h}$. Chemokine concentrations in the cell supernatants were determined by ELISA $(n=4)$. Data is presented as mean \pm SEM

whether the released nucleotides ATP/ADP are responsible for the increased migration of $\mathrm{P} 2 \mathrm{Y}_{12}{ }^{+}$Raw 264.7 cells towards dying tumor cells, we added the ATP/ADPhydrolyzing enzyme apyrase to the culture medium of the puromycin-pretreated B16F1 cells. Addition of apyrase significantly reduced the migration of $\mathrm{P} 2 \mathrm{Y}_{12} 2^{+}$Raw 264.7 cells (Fig. 7a, b). Also, treatment of P2Y12 ${ }^{+}$Raw 264.7 cells with the P2Y12 antagonists PSB0739 or cangrelor significantly diminished the migration (Fig. 7c). To determine whether ADP is the cause of increased migration of $\mathrm{P}^{2} \mathrm{Y}_{2}{ }^{+}$Raw 264.7 cells towards dying melanoma cells, we measured ADP levels in the cell supernatants of dying and viable B16F1 cells. Increased ADP concentrations were detected in the supernatants of puromycin-treated tumor cells $(118 \mathrm{nM}$ ADP) when compared to untreated cells (26 nM ADP) (Fig. 7d). Using these concentrations, we performed transwell migration assays and confirmed increased migration of $\mathrm{P} 2 \mathrm{Y}_{12} 2^{+}$Raw 264.7 cells towards $118 \mathrm{nM}$ ADP compared to $26 \mathrm{nM}$ ADP (Fig. 7e). These results indicate that dying tumor cells release ADP that attracts macrophages via their P2Y12 receptor.

\section{Discussion}

TAM are prominent components of the tumor microenvironment known to support tumor growth and progression. Therefore, the aim of the current study was to identify novel markers on TAM that can be used as therapeutic targets. Previously, we could show that several M2 macrophage markers expressed by TAM of melanoma in situ can be induced in pBM by MDI in vitro ${ }^{21}$. By gene expression analysis of $\mathrm{pBM}_{(\mathrm{MDI})}$, we identified the purinergic receptor P2Y12 as the highest up-regulated gene. On protein level, this ADP receptor has only been verified on platelets and microglia so far but not on other human macrophages including $\mathrm{TAM}^{20,22}$. This is probably due to a lack of commercially available specific antibodies targeting human P2Y12. Using our selfgenerated anti-hsP2Y12 antibody we were the first to identify P2Y12 protein expression in human $\mathrm{pBM}_{(\mathrm{MDI})}$ as well as in TAM of melanoma. Various in vitro studies showed that dexamethasone induces an immunosuppressive M2 macrophage phenotype ${ }^{23}$. Although dexamethasone alone was not sufficient to induce P2Y12 expression in $\mathrm{pBM}$, the glucocorticoid receptor inhibitor mifepristone significantly suppressed P2Y12 induction upon MDI treatment indicating that glucocorticoids are indispensable for P2Y12 induction. We detected P2Y12 in $\mathrm{CD} 8^{+} \mathrm{CD} 163^{+}$TAM of primary melanoma as well as melanoma metastases. Not all $\mathrm{CD} 68^{+}$macrophages were P2Y12 positive suggesting that this receptor is only expressed on a distinct macrophage subpopulation. Recently, researchers found that glucocorticoid synthesis is also induced in the skin during inflammation or upon exposure to inflammatory stimuli including UV irradia$\operatorname{tion}^{24}$. Thus, it is possible that local glucocorticoid synthesis in cutaneous melanoma supports macrophage polarization towards an anti-inflammatory M2 phenotype and induces P2Y12. This hypothesis has to be verified using specific knock out mice.

In microglial cells, ADP binding to P2Y12 has been shown to prompt the release of various cytokines and chemokines ${ }^{25,26}$. By gene expression analysis, we also identified up-regulation of several cytokines and chemokines including CXCL2, CXCL7, and CXCL8 in 2MeSADP-treated P2Y12 ${ }^{+}$U937 cells accompanied by increased protein concentrations in the cell supernatants of these cells. Investigating signaling pathways that lead to the up-regulation of the chemokines in $\mathrm{P} 2 \mathrm{Y}_{12}{ }^{+}$macrophages, we detected both increased ERK1/2 as well as Akt phosphorylation in 2-MeSADP-treated $\mathrm{P}^{\mathrm{Y} 12^{+}} \mathrm{U} 937$ cells as well as an increased expression of the AP-1 transcription factor subunits JUN and FOSL1. In line with our results, P2Y12 agonists induced PI3K/Akt signaling in platelets and microglial cells ${ }^{27,28}$. In addition, Soulet et al. ${ }^{10}$ showed that besides Akt, ERK $1 / 2$ is phosphorylated upon treatment of transgenic $\mathrm{P}_{2} \mathrm{Y}^{+}{ }^{+} \mathrm{CHO}$ cells with 2-MeSADP. In our hands, this 2-MeSADP-induced ERK/Akt phosphorylation was responsible for the upregulation of CXCL2, CXCL7, and CXCL8 as ERK and Akt blockade inhibited the 2-MeSADP-dependent secretion of these cytokines in P2Y12 $2^{+}$U937 cells. By releasing these chemokines, $\mathrm{P} 2 \mathrm{Y}_{12}{ }^{+}$macrophages might exert protumoral functions since CXCL2, CXCL7, and CXCL8 are implicated in chemotaxis of neutrophils and in angiogenesis. Since both neutrophil infiltration and angiogenesis support tumor growth and progression, blocking the release of these chemokines with P2Y12 antagonists 
a

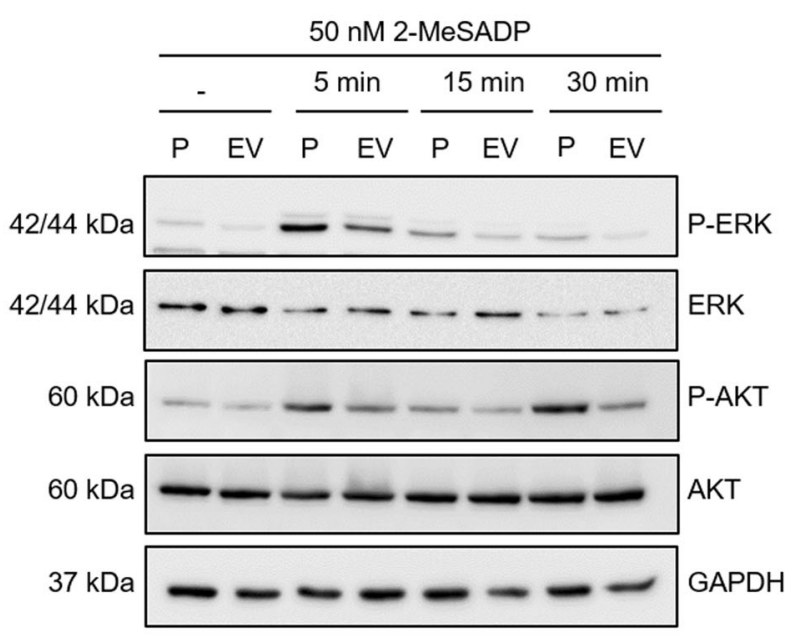

b

U937 P2Y12 U937 EV

FOSL1

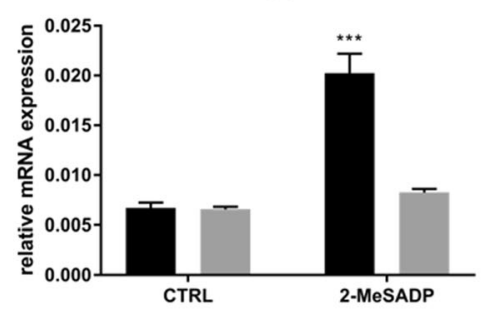

C

FOSL1

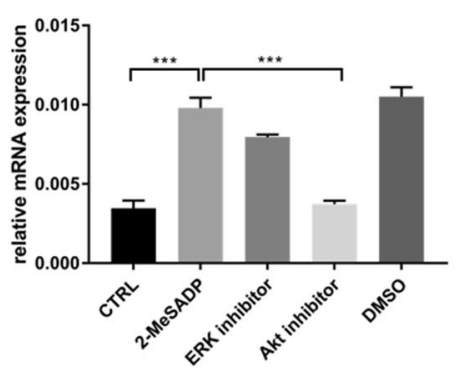

JUN

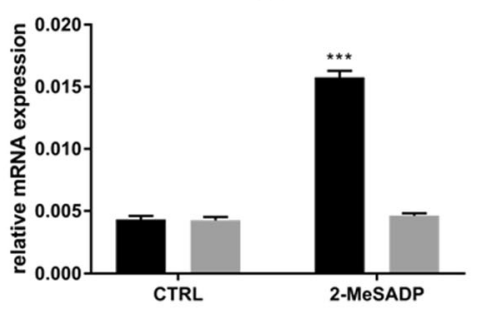

UN

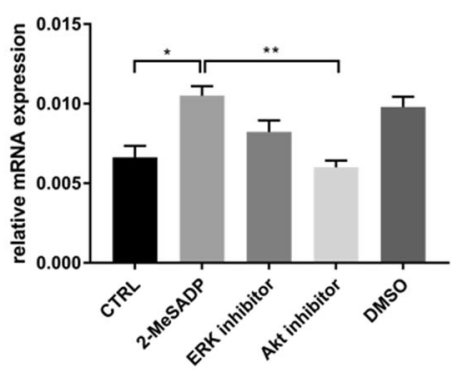

d
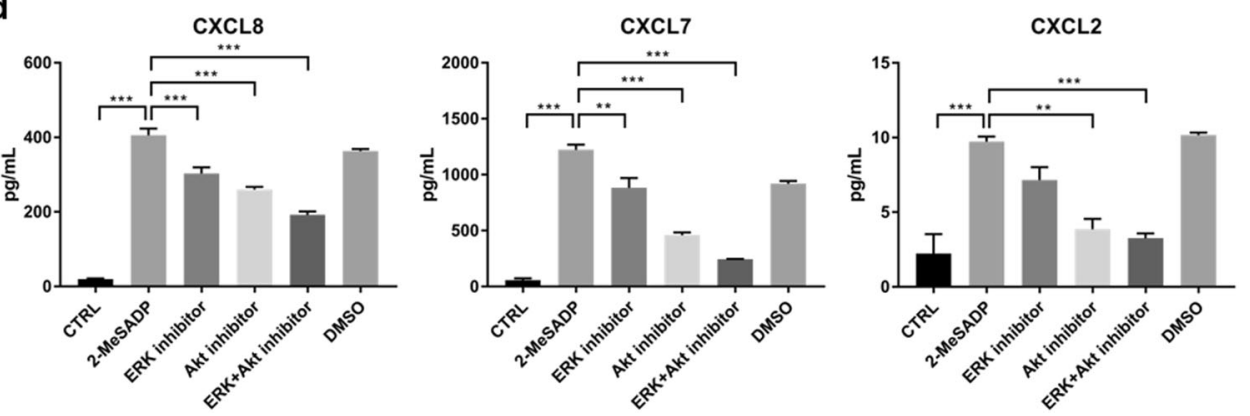

Fig. 5 (See legend on next page.) 
(see figure on previous page)

Fig. 5 Blockade of ADP-induced ERK and Akt signaling inhibits chemokine secretion in P2Y12 ${ }^{+}$U937 cells. a Transgenic U937 cells were treated with $50 \mathrm{nM}$ 2-MeSADP for the indicated time points and western blot analysis was performed using anti-P-ERK1/2, anti-ERK1/2, anti-P-Akt, and anti-Akt antibodies. GAPDH served as loading control. One representative Western blot is shown $(n=3) . P=P 2 Y 12^{+}$U937 cells, EV $=$empty vector U937 cells. b Transgenic U937 cells were treated with 50 nM 2-MeSADP for $4 \mathrm{~h}$ and expression of JUN and FOSL1 was assessed by qRT-PCR. Gene expression was normalized to GAPDH $(n=3)$. c P2Y12 12937 cells were pretreated with $1 \mu \mathrm{M}$ ERK inhibitor or $1 \mu \mathrm{M}$ Akt inhibitor prior to stimulation with $50 \mathrm{nM}$ 2-MeSADP for $4 \mathrm{~h}$. Gene expression of the transcription factors JUN and FOSL1 was assessed by qRT-PCR. Gene expression was normalized to GAPDH $(n=3)$. d P2Y12 $12^{+}$U937 cells were pretreated with $1 \mu \mathrm{M}$ ERK inhibitor, $1 \mu \mathrm{M}$ Akt inhibitor or both prior to stimulation with $50 \mathrm{nM}$ 2-MeSADP for $24 \mathrm{~h}$. Cell supernatants were collected, and chemokine concentrations were determined by ELISA $(n=3)$. Data is presented as mean \pm SEM

might attenuate tumor growth. Indeed, treatment of P2Y12 ${ }^{+}$U937 cells with the P2Y12 antagonist PSB0739 abrogated the 2-MeSADP-induced release of CXCL2, CXCL7, and CXCL8. Several clinically approved P2Y12 antagonists including clopidogrel and ticagrelor were reported to have anti-inflammatory properties indicating that $\mathrm{P} 2 \mathrm{Y}_{12}{ }^{+}$cells are important mediators of inflammation. Clopidogrel reduced airway inflammation by decreasing levels of the Th2 cytokines IL-4 and IL-13 as well as IFN- $\gamma$ and CCL5 in a mouse model of asthma ${ }^{29}$. Ticagrelor attenuated atherogenesis in ApoE-deficient mice. This was accompanied by decreased expression of CCL2 and reduced accumulation of macrophages ${ }^{30}$. In the brain, ticagrelor treatment reduced the number of infiltrating microglia and the expression of IL-1ß, CCL2, and iNOS after cerebral artery occlusion ${ }^{26}$. Together, these results indicate that P2Y12 is involved in the modulation of the immune microenvironment in various pathological inflammatory conditions. In $\mathrm{P} 2 \mathrm{Y}^{+} 2^{+}$microglia cells ADP does not only induce the secretion of inflammatory mediators but also directly acts as a chemoattractant triggering migration of these cells to the site of nerve injury ${ }^{12,31,32}$. We showed that 2-MeSADP also acts as a chemoattractant for $\mathrm{P}^{2} 12^{+} \mathrm{pBM}_{(\mathrm{MDI})}$ as well as P2Y12 ${ }^{+}$Raw 264.7 cells. It is well known that phagocytic cells express purinergic receptors which allow the sensing of nucleotides released by apoptotic and necrotic cells during inflammatory conditions ${ }^{33}$. Zhang et al. $^{34}$ demonstrated that ADP enhanced the recruitment of macrophages and to a lesser extend neutrophils to the site of bacterial infection in vivo suggesting that the ADP receptors P2Y12 and P2Y13 are responsible for this effect. In addition, it was shown that recruited macrophages secrete chemokines such as CXCL2 and CXCL8, which is in line with our findings ${ }^{35,36}$.

Especially in hypoxic areas of rapidly growing tumors such as melanoma the microenvironment is rich in nucleotides released by dying tumor as well as stromal cells ${ }^{37}$. We demonstrated that $\mathrm{P}^{2} \mathrm{Y}^{+} 2^{+}$macrophages migrate towards dying melanoma cells pretreated with puromycin. Since apyrase abrogated this cell deathinduced migration and increased ADP levels were detected in the supernatants of dying cells we provided proof that dying tumor cells release ADP that acts as a find-me signal for $\mathrm{P} 2 \mathrm{Y}_{1} 2^{+}$macrophages. Similar to our findings Elliott et al. ${ }^{38}$ showed that apoptotic cell supernatants induce the migration primarily of macrophages in vivo. Although macrophages of $\mathrm{P} 2 \mathrm{Y} 2^{-1-}$ mice showed impaired migration towards apoptotic cell supernatants, the migration was not completely abrogated, suggesting the involvement of other nucleotide receptors. Since we showed that P2Y12 is expressed on human TAM and necrotic cell death induces the migration of $\mathrm{P} 2 \mathrm{Y}_{12}{ }^{+}$ macrophages, which can be inhibited with the P2Y12 antagonist cangrelor, P2Y12 might also be involved in the sensing of apoptotic cells in the tumor microenvironment. Whether P2Y12 antagonists reduce the migration of $\mathrm{P} \mathrm{Y}_{12}{ }^{+}$macrophages to the site of tumor in vivo and whether $\mathrm{P} 2 \mathrm{Y}_{12}{ }^{+}$macrophages promote tumor growth and progression needs to be determined using appropriate mouse models. Regarding cancer it was shown by others that tumor growth and metastasis are reduced in P2Y12 ${ }^{-1-}$ mice $^{39,40}$. In addition, the P2Y12 antagonist ticagrelor reduced metastasis in WT mice ${ }^{41}$. These effects were mainly linked to platelets and not to other P2Y12expressing hematopoietic cells.

In contrast to these preclinical studies demonstrating an anti-tumoral effect, several clinical trials investigating the effect of dual anti-platelet therapy on cancer incidence concluded that there might be a higher cancer risk with newer anti-platelet drugs such as prasugrel or ticagrelor $^{16-18}$. Whether blockade of specific function of P2Y12 ${ }^{+}$macrophages contribute to this increased cancer risk remains to be elucidated in further studies.

Taken together, our results indicate that P2Y12 is an important immunomodulatory macrophage receptor, which triggers migration of these cells towards ADP-rich tumor areas and is able to modulate the inflammatory environment upon ADP binding.

\section{Materials and methods \\ Cell lines}

The human monocytic cell line U937 (CRL-1593.2 ${ }^{\mathrm{TM}}$, $\mathrm{ATCC}^{\circledR}$, Wesel, Germany) was cultured in RPMI-1640 Medium (Gibco by Thermo Fisher Scientific, Darmstadt, Germany) supplemented with $10 \%$ fetal calf serum (FCS, 
a

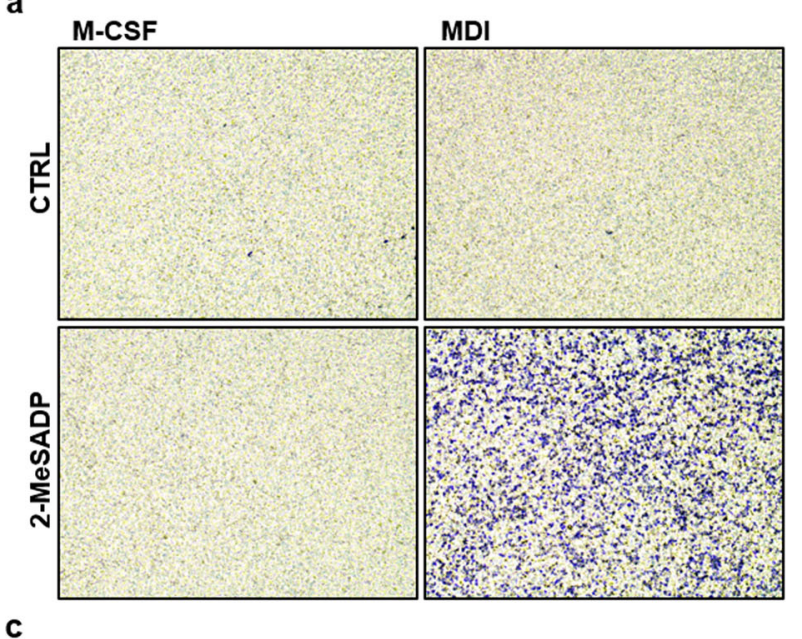

c

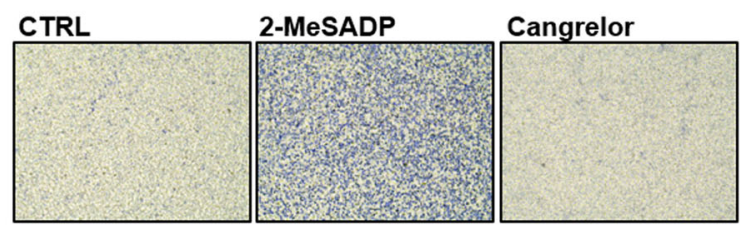

e

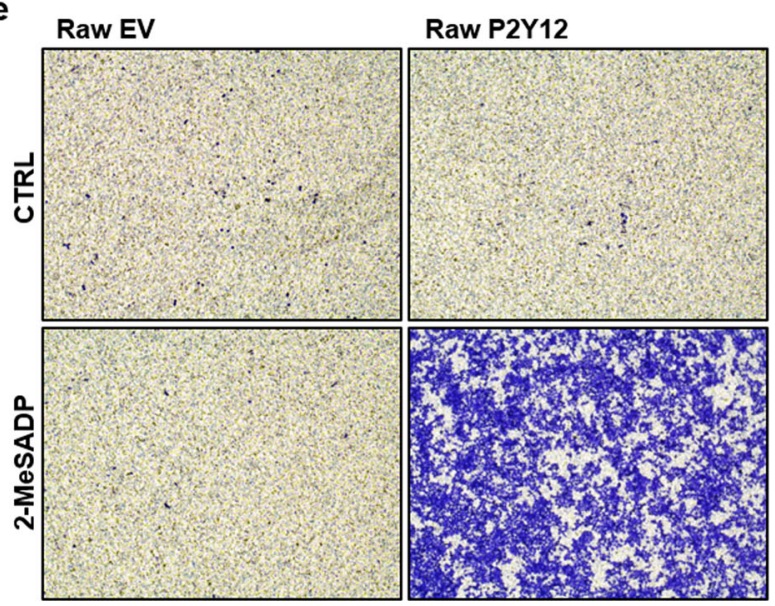

b
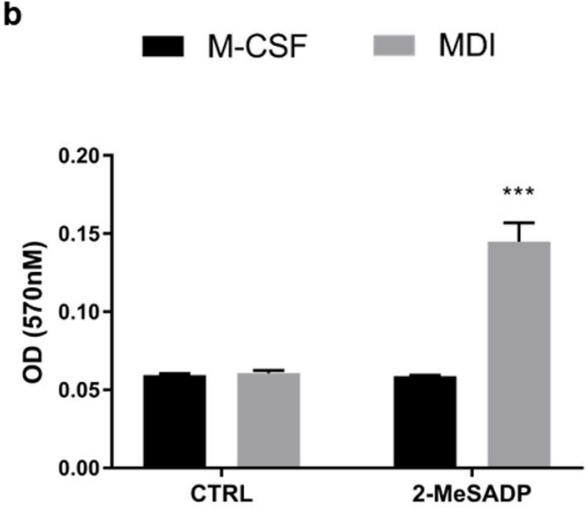

d

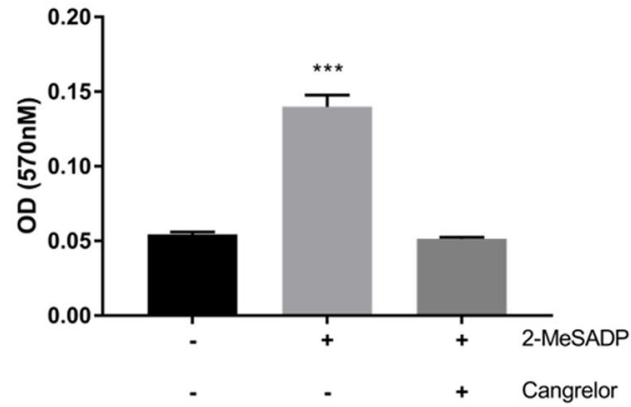

f

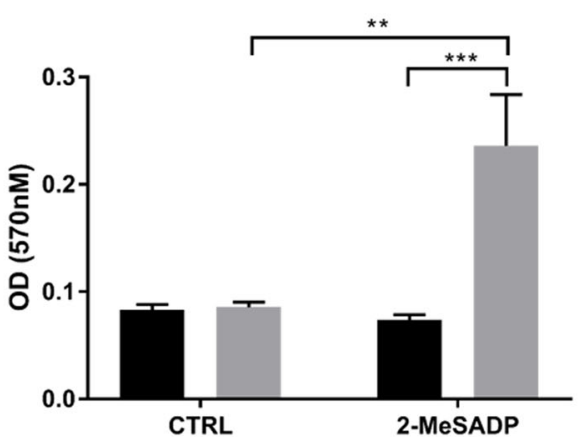

Fig. 6 ADP promotes migration of $\mathrm{P} 2 \mathrm{Y}_{12}{ }^{+}$macrophages. $\mathbf{a}$, $\mathbf{b}$ pBM were treated with M-CSF or MDI for 7 days and then seeded in the insert of a transwell chamber. $50 \mathrm{nM}$ 2-MeSADP was added to the medium in the lower chamber. Migration was assessed after $6 \mathrm{~h}$ by fixing the cells at the bottom of the transwell membrane with methanol followed by staining with crystal violet. a Pictures of the stained migrated cells at the bottom of the transwell membrane were taken using an inverted microscope $(n=6)$. $\mathbf{b}$ Crystal violet was resolved with methanol and absorbance at $570 \mathrm{~nm}$ was measured by microplate reader $(n=6)$. $\mathbf{c}, \mathbf{d} \mathrm{pBM}_{(\mathrm{MDI})}$ were seeded in the insert of a transwell chamber and $10 \mu \mathrm{M}$ cangrelor and/or $50 \mathrm{nM} 2-$ MeSADP were added to the medium in the lower chamber. Migration was assessed after $6 \mathrm{~h}$ by fixing the cells at the bottom of the transwell membrane with methanol followed by staining with crystal violet. c Pictures of the stained migrated cells at the bottom of the transwell membrane were taken using an inverted microscope $(n=3)$. d Crystal violet was resolved with methanol and absorbance at $570 \mathrm{~nm}$ was measured by microplate reader $(n=3)$. e, f Transgenic Raw 264.7 cells were seeded in transwell inserts. 50 nM 2-MeSADP was added to the medium of the lower chamber. Migration was assessed after $16 \mathrm{~h}$ by fixing the cells at the bottom of the transwell membrane with methanol followed by staining with crystal violet. e Pictures of the stained migrated cells at the bottom of the transwell membrane were taken using an inverted microscope $(n=6)$. f Crystal violet was then resolved with $100 \%$ methanol and absorbance at $570 \mathrm{~nm}$ was measured by microplate reader $(n=6)$. Data is presented as mean \pm SEM 

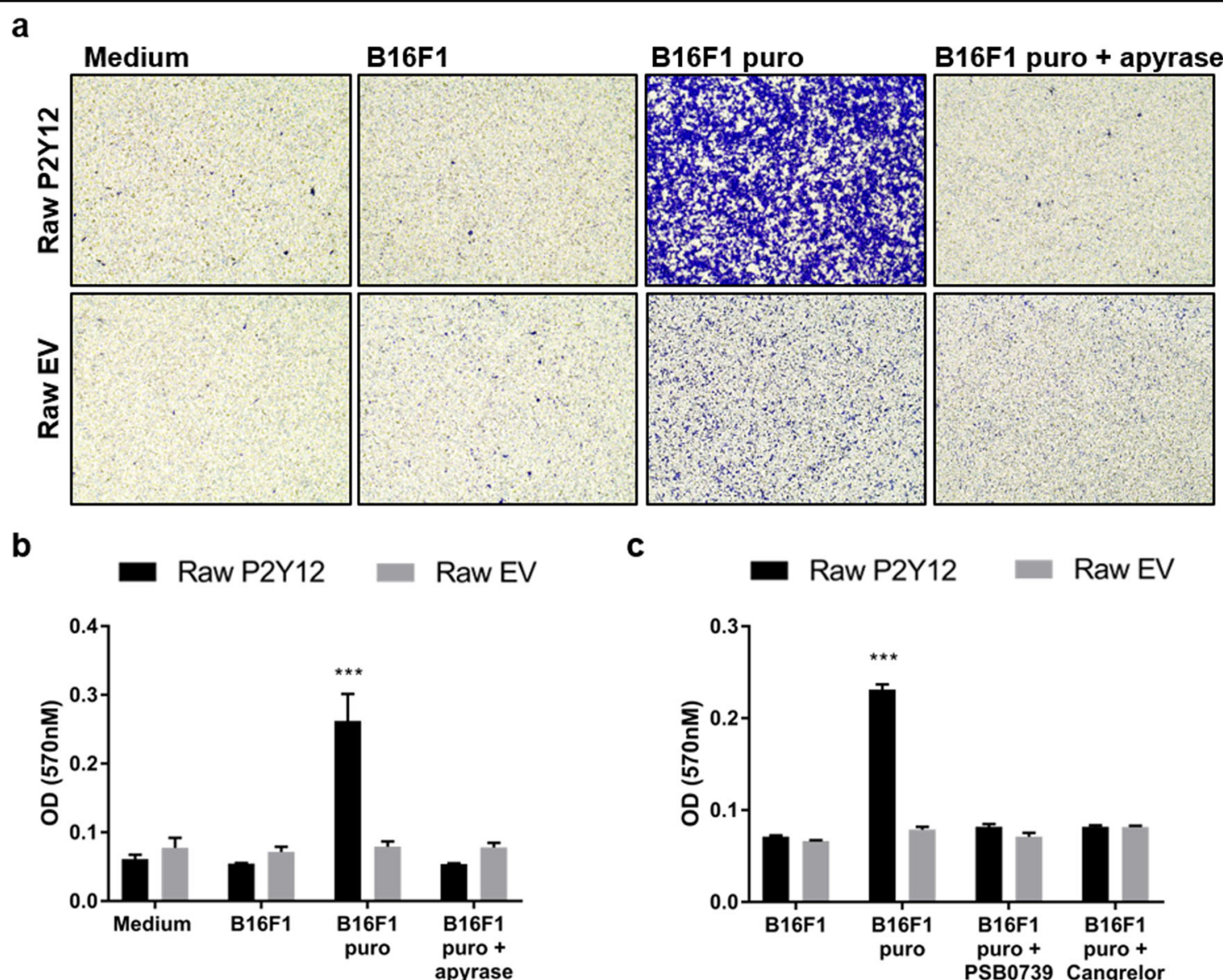

C

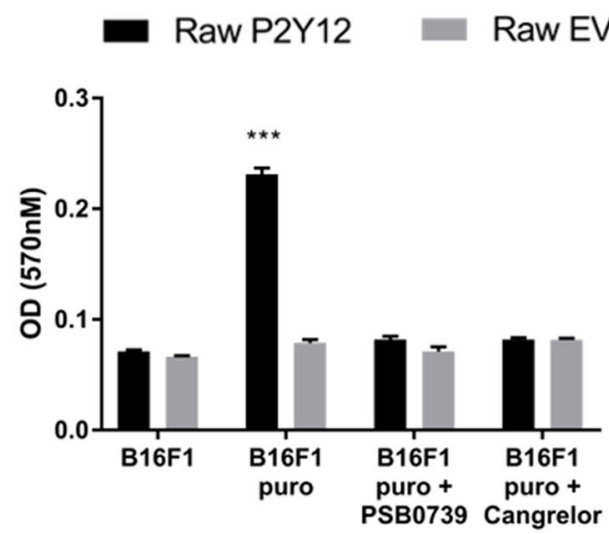

d

e
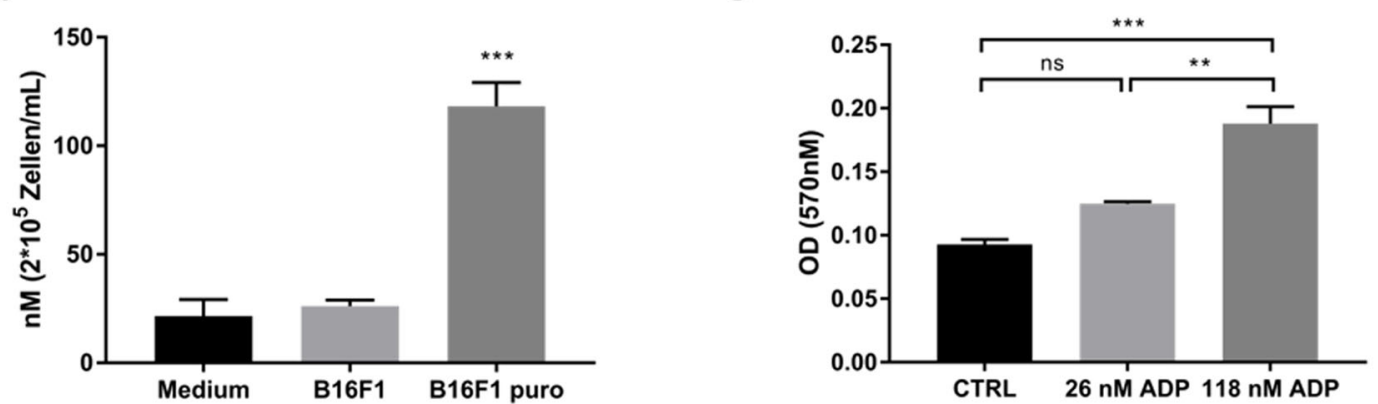

Fig. 7 ADP released by dying tumor cells promote the migration of $\mathbf{P} 2 \mathbf{Y}^{12} \mathbf{2}^{+}$Raw $\mathbf{2 6 4 . 7}$ cells. a-c B16F1 were treated with $2 \mu \mathrm{g} / \mathrm{mL}$ puromycin (puro) for $24 \mathrm{~h}$ to induce cell death. $1 \mathrm{U} / \mathrm{mL}$ apyrase, $10 \mu \mathrm{M}$ PSB0739, or $10 \mu \mathrm{M}$ cangrelor were added to the puro-treated B16F1 cells. Untreated B16F1 cells and medium without cells served as controls. Transgenic EV or P2Y12 ${ }^{+}$Raw 264.7 cells were seeded in transwell inserts which were then placed in the 24-well plate containing the B16F1 cells or medium alone. Migration was assessed after $6 \mathrm{~h}$ by fixation of the migrated cells with methanol followed by staining with crystal violet. a Pictures of the migrated cells at the bottom of the transwell membrane were taken using an inverted microscope $(n=6)$. (b-c) Crystal violet was then resolved with 100\% methanol and absorbance at $570 \mathrm{~nm}$ was measured by microplate reader $(n=6)$. $\mathbf{d}$ Supernatants of untreated and puro-treated B16F1 cells were collected and ADP concentrations were assessed using ADP Assay Kit. Medium was used as a control $(n=4)$. e P $2 Y_{12} 2^{+}$Raw 264.7 cells were seeded in transwell inserts and $26 \mathrm{nM}$ and $118 \mathrm{nM}$ ADP was added to the medium of the lower chamber. Migration was assessed after $6 \mathrm{~h}$ by fixing the cells at the bottom of the transwell membrane with methanol followed by staining with crystal violet. Crystal violet was then resolved with methanol and absorbance at $570 \mathrm{~nm}$ was measured by microplate reader $(n=3)$. Data is presented as mean \pm SEM 
Biochrom, Berlin, Germany), $100 \mathrm{U}$ penicillin, as well as 100 mg/L streptomycin (Pen/Strep, Biochrom, Berlin, Germany). The murine macrophage-like cell line RAW 264.7 (TIB-71 $^{\mathrm{Tm}}$, ATCC ${ }^{\oplus}$, Wesel, Germany) and the murine melanoma cell line B16F1 (CRL-6323 ${ }^{\mathrm{TM}}$, ATCC $^{\oplus}$, Wesel, Germany) were cultivated in DMEM (Gibco by Thermo Fisher Scientific, Darmstadt, Germany) with 10\% FCS, 1\% Pen/Strep (DMEM complete). All cell lines were cultivated at $37^{\circ} \mathrm{C}$ in an atmosphere enriched with $5 \% \mathrm{CO}_{2}$.

\section{Isolation of human peripheral blood monocytes}

$\mathrm{CD}_{14}{ }^{+}$cells were isolated from buffy coats of healthy donors obtained from Red Cross Blood Service, BadenWürttemberg. Peripheral blood mononuclear cells (PBMC) were separated by density gradient centrifugation and monocytes were isolated by magnetic-activated cell sorting (MACS) using anti-CD14 MicroBeads (Miltenyi, BergischGladbach, Germany). For differentiation, $1 \times 10^{6}$ cells $/ \mathrm{mL}$ were seeded in $\mathrm{X}-\mathrm{VIVO}^{\mathrm{TM}} 15$ medium (Lonza, Cologne, Germany) and stimulated with M-CSF $(100 \mathrm{ng} / \mathrm{mL}$, Peprotech, Hamburg, Germany), IL-4 (10 ng/mL, Peprotech, Hamburg, Germany), dexamethasone $\left(1 \times 10^{-7} \mathrm{M} ; 1000 \mathrm{U} /\right.$ $\mathrm{mL}$, Sigma-Aldrich, Munich, Germany), IFN- $\gamma(10 \mathrm{ng} / \mathrm{mL}$, Peprotech, Hamburg, Germany), LPS ( $1 \mu \mathrm{g} / \mathrm{mL}$ Invitrogen by Thermo Fisher Scientific, Darmstadt, Germany), TNF- $\alpha$ (10 ng/mL, Peprotech, Hamburg, Germany), IL-10 (10 ng/ mL, Peprotech, Hamburg, Germany), TGF-ß (100 ng/mL, Peprotech, Hamburg, Germany), and Mifepristone (100 nM, Sigma-Aldrich, Munich, Germany) for 7 days at $37^{\circ} \mathrm{C}$ in an atmosphere of $7.5 \% \mathrm{CO}_{2}$.

\section{Human samples}

The study was performed according to federal laws and regulations as well as institutional policies. We obtained ethical approval from the local ethical committee (reference number: 2010-318N-MA). Written informed consent was obtained from all patients and data was analyzed anonymously.

\section{Generation of anti-hsP2Y12 antibody}

A polyclonal antibody against human P2Y12 was generated in rabbit, targeting the peptide sequence SQDNRKKEQDGGDPNEETPM referring to amino acid 323-342 of the C-terminus (sequence ID NP_073625.1). The synthetized peptide was coupled to KLH carrier protein and used as immunogen in a commercial process (Peptide Specialties Laboratory (PSL), Heidelberg, Germany). The polyclonal anti-hsP2Y12 antibody was purified by affinity chromatography using a peptide specific column (PSL, Heidelberg, Germany).

\section{Immunocytochemistry}

Transgenic U937 cells were centrifuged onto glass slides as cytospins. The slides were washed with PBS, fixed with acetone for $10 \mathrm{~min}$ and washed two times with PBS. Subsequently, cytospins were treated with peroxidase blocking solution (Dako by Agilent, Waldbronn, Germany), blocked with $2 \%$ BSA, and incubated with antihsP2Y12 antibody for $2 \mathrm{~h}$ at RT. To test the specificity of the anti-P2Y12 antibody, it was preincubated with the blocking peptide. After incubation with the anti-rabbit HRP-labeled secondary antibody (Dako by Agilent, Waldbronn, Germany) for $1 \mathrm{~h}$ at RT, AEC chromogen solution (Dako by Agilent, Waldbronn, Germany) was applied for visualization. 10\% Mayer's Haemalaun (Merck, Darmstadt, Germany) was used for counterstaining. Pictures were taken with a Leica DCRE microscope, Leica DC500 camera, and software system (Leica, Wetzlar, Germany).

\section{Immunohistochemistry}

Formalin-fixed paraffin embedded (FFPE) human tissue samples were dewaxed using a decreasing xylene/alcohol series followed by heat-induced antigen retrieval $(\mathrm{pH} 6)$. Subsequently, specimens were treated with peroxidase blocking solution (Dako by Agilent, Waldbronn, Germany), blocked with $2 \%$ BSA and incubated with primary antibodies (anti-hsP2Y12 or anti-hsCD68) for $2 \mathrm{~h}$ at RT. Rabbit IgG (Dianova, Hamburg, Germany) was used as an isotype control for the anti-hsP2Y12 antibody. After incubation with the appropriate HRP-labeled secondary antibody (for hsP2Y12 anti-rabbit HRP, for hsCD68 antimouse HRP, both Dako by Agilent, Waldbronn, Germany) for $1 \mathrm{~h}$ at RT, AEC chromogen solution (Dako by Agilent, Waldbronn, Germany) was applied for visualization. 10\% Mayer's Haemalaun (Merck, Darmstadt, Germany) was used for counterstaining. Pictures were taken with a Leica DCRE microscope, Leica DC500 camera, and software system (Leica, Wetzlar, Germany).

\section{Sequential staining}

FFPE melanoma sections were prepared as described before. Samples were blocked with 5\% skimmed milk powder in PBS and incubated with the desired primary antibody [self-generated rabbit anti-hsP2Y12, mouse antihsCD163 (Leica, Wetzlar, Germany), mouse anti-hsCD68 (Dako by Agilent, Waldbronn, Germany)] diluted in antibody diluent (Dako by Agilent, Waldbronn, Germany) either for $2 \mathrm{~h}$ at $\mathrm{RT}$ or overnight at $4{ }^{\circ} \mathrm{C}$. The samples were incubated with peroxidase blocking solution (Dako by Agilent, Waldbronn, Germany) followed by incubation with the appropriate HRP-labeled secondary antibody diluted in antibody diluent (Dako by Agilent, Waldbronn, Germany) for $1 \mathrm{~h}$ at RT. Samples were incubated with VECTOR NovaRED Peroxidase Solution (Vector laboratories, Peterborough, UK) and counterstained using 10\% Mayer's Haemalaun (Merck, Darmstadt, Germany). After pictures were taken with the Nikon Eclipse NI microscope 
specimens were destained in stripping buffer [2\% SDS, $62.5 \mathrm{mM}$ Tris-HCL (pH 7.5), 0.8\% ß-mercaptoethanol] for $1 \mathrm{~h}$ at $50{ }^{\circ} \mathrm{C}$ and used again to stain another antigen.

\section{Immunofluorescence}

FFPE melanoma sections were prepared as described before. Blocking was performed with $5 \%$ donkey serum in PBS. Primary antibodies [self-generated rabbit antihsP2Y12 and mouse anti-hsCD163 (Leica, Wetzlar, Germany)] were incubated at $4{ }^{\circ} \mathrm{C}$ overnight. Subsequently, the samples were treated with the corresponding fluorochrome-conjugated secondary antibody [donkey anti-rabbit Alexa488 and donkey anti-mouse Cy3 (both Dianova, Hamburg, Germany)]. Images were taken with the Nikon Eclipse NI microscope with the Clara interline CCD camera (Andor, Belfast, UK) and NIS-Elements Advanced software (Nikon, Düsseldorf, Germany).

\section{In situ hybridization}

In situ hybridization was performed with the RNAscope $^{\circledast} 2.5$ HD Detection Kit (ACDbio, Newark, CA, USA) to visualize P2Y12 mRNA in melanoma specimens. Initially, FFPE tissue samples were deparaffinized with xylene and $100 \%$ ethanol and the slides were air-dried. Then, RNAscope ${ }^{\circledast}$ Hydrogen Peroxide (ACDbio, Newark, CA, USA) was applied and the antigen retrieval were performed by boiling in RNAscope ${ }^{\circledR}$ Target Retrieval Reagent (ACDbio, Newark, CA, USA) for 15 min followed by incubation with RNAscope ${ }^{\circledR}$ Protease Plus Reagent (ACDbio, Newark, CA, USA) for $30 \mathrm{~min}$. The P2Y12 probe (Hs-P2Y12 targeting 121-1283, Entrez Gene ID 64805) was hybridized for $2 \mathrm{~h}$ at $40^{\circ} \mathrm{C}$ and the signal was amplified and detected with RED-A and RED-B solution (ACDbio, Newark, CA, USA) followed by counterstaining with $50 \%$ hematoxylin. Pictures were taken with a Leica DCRE microscope, Leica DC500 camera, and software system (Leica, Wetzlar, Germany).

\section{Western blot analysis}

Cells were lysed with RIPA buffer (Sigma-Aldrich, Munich, Germany) containing protease and phosphatase inhibitors (Roche, Mannheim, Germany). For some experiments, denaturated cell lysates were treated with $1 \mu \mathrm{L}$ PNGase F (Sigma-Aldrich, Munich, Germany) and incubated at $37^{\circ} \mathrm{C}$ for $24 \mathrm{~h}$ to achieve deglycosylation of the proteins. Proteins were separated by gel electrophoresis using 10\% SDS-polyacrylamide gels. After semi-dry blotting (Bio-Rad, Dreieich, Germany) onto PVDF membranes (GE Healthcare, Little Chalfont, UK), the blots were incubated with primary antibodies [selfgenerated rabbit anti-hsP2Y12, anti-GAPDH, anti-PERK1/2, anti-ERK, anti-P-Akt, anti-Akt (Cell Signaling Technology, Danvers, MA, USA)] overnight at $4{ }^{\circ} \mathrm{C}$. To test the specificity of the anti-P2Y12 antibody it was preincubated with the blocking peptide. Subsequently, blots were incubated with the secondary antibodies anti-rabbit HRP (GE Healthcare, Little Chalfont, UK) and for signal detection Luminata Forte Western HRP Substrate (Merck, Darmstadt, Germany) was applied. Signal detection was performed using c600 WesternBlot Imaging System (Azure Biosystems, Dublin, CA, USA).

\section{Quantitative RT-PCR analysis}

RNA was isolated using innuPREP RNA Mini Kit (Jena Analytik, Jena, Germany) according to the manufacturer's protocol. For reverse transcription $500 \mathrm{ng}$ of RNA per sample was used. The reaction was performed using Maxima Reverse Transcriptase and Oligo $(\mathrm{dT})_{18}$ primer (both Thermo Fisher Scientific, Munich, Germany). Template cDNA was diluted $1: 50$ in $d_{d d} \mathrm{H}_{2} \mathrm{O}$, mixed with primers $(2 \mu \mathrm{M})$, as well as SyBRGreen Master Mix (Applied Biosystems by Thermo Fisher Scientific, Munich, Germany) according to the manufacturer's instructions. The PCR was performed under standard conditions in a MX3000P sequence detection system (Stratagene by Agilent, Waldbronn, Germany). For normalization of the template amount, gene expression was calculated in relation to the housekeeping gene $\beta$-actin or GAPDH. Primers are listed in Supplementary Table 2.

\section{Generation of transgenic cell lines}

Human P2Y12 cDNA (clone IRAUp969F0383D) and murine P2Y12 cDNA (IRAVp968D0977D, both from SourceBioscience, Nottingham, UK) was amplified by PCR and cloned into vector lentivirus ADR3 as described previously $^{21}$. For lentiviral transfection, HEK293/T17 producer cells were transfected with the ADR3 vector carrying the P2Y12 gene and 3rd generation lentiviral plasmids (pMD2.G L1, pRSV rev L2, pMDLg/pRRE L3 and pCDNA3.1/p35 E 71) using X-treme GENE 9 DNA transfection reagent (Roche, Mannheim, Germany). After U937 and RAW 264.7 were infected with the produced lentiviruses positive selection was performed using puromycin $(2 \mu \mathrm{g} / \mathrm{mL}$, Thermo Fisher Scientific, Munich, Germany).

\section{Enzyme-linked immunosorbent assay}

In all, $1 \times 10^{6}$ transgenic U937 cells were seeded in $2 \mathrm{~mL}$ RPMI complete and stimulated with $50 \mathrm{nM}$ 2-MeSADP (Bio-Techne, Wiesbaden, Germany) for $24 \mathrm{~h}$. Cell supernatants were collected and centrifuged at $1000 \times g$ for $10 \mathrm{~min}$ to obtain cell free supernatants. All ELISAs were performed according to the manufacturer's instructions. (human CXCL8/CXCL2/CXCL7 DuoSet ELISA, R\&D Systems, Wiesbaden, Germany). 


\section{Microarray analysis}

Transgenic U937 cells were seeded at a concentration of $1 \times 10^{6}$ cells $/ \mathrm{mL}$ and stimulated with $50 \mathrm{nM} 2$-MeSADP (Bio-Techne, Wiesbaden, Germany) for $4 \mathrm{~h}$. pBM were seeded at a concentration of $1 \times 10^{6}$ cells $/ \mathrm{mL}$ and stimulated with M-CSF and MDI for 7 days as described before. Gene expression profiling was performed using arrays of human HuGene-2_0-st-type (Thermo Fisher Scientific, Waltham, MA, USA). Biotinylated antisense cDNA was then prepared according to the standard labeling protocol with the GeneChip ${ }^{\circledR}$ WT Plus Reagent Kit and the GeneChip ${ }^{\circledR}$ Hybridization, Wash and Stain Kit (both from Thermo Fisher Scientific, Waltham, MA, USA). Afterwards, the hybridization on the chip was performed on a GeneChip Hybridization oven 640, then dyed in the GeneChip Fluidics Station 450 and thereafter scanned with a GeneChip Scanner 3000. All of the equipment used was from the Affymetrix-Company (Affymetrix, High Wycombe, UK). A Custom CDF Version 20 with ENTREZ based gene definitions was used to annotate the arrays $^{42}$. The raw fluorescence intensity values were normalized applying quantile normalization and RMA background correction. OneWay-ANOVA was performed to identify differential expressed genes using a commercial software package SAS JMP10 Genomics, version 6, from SAS (SAS Institute, Cary, NC, USA). A false positive rate of $a=0.05$ with FDR correction was taken as the level of significance. Gene Set Enrichment Analysis (GSEA) was used to determine whether defined lists (or sets) of genes exhibit a statistically significant bias in their distribution within a ranked gene list using the software GSEA $^{43}$.

\section{Transwell migration assay with $\mathrm{pBM}$}

$\mathrm{CD} 14^{+}$cells were isolated and differentiated as described before. After seven days of stimulation, MDI- and M-CSF-treated pBM were harvested and $2 \times 10^{5}$ cells were seeded in $6.5 \mathrm{~mm}$ transwell inserts with a $5-\mu \mathrm{m}$ pore size (Corning, Wiesbaden, Germany). X-VIVO medium supplemented with $50 \mathrm{nM}$ 2-MeSADP (Bio-Techne, Wiesbaden, Germany) was used as a chemoattractant in the lower chamber of the transwell. For some experiments $\mathrm{pBM}_{(\mathrm{MDI})}$ were pretreated with $10 \mu \mathrm{M}$ cangrelor (BioTechne, Wiesbaden, Germany). Migration was assessed after $6 \mathrm{~h}$ by fixing the cells with $100 \%$ methanol, followed by staining with $5 \%$ crystal violet. Pictures of migrated cells were taken using an inverted microscope (Zeiss Axiovert). Crystal violet was then dissolved in methanol and quantified measuring the absorbance at $570 \mathrm{~nm}$ by TECAN microplate reader.

Transwell migration assay with transgenic Raw 264.7 cells In all, $5 \times 10^{5}$ transgenic Raw 264.7 cells were seeded in DMEM w/o FCS in the upper chamber of a $6.5-\mathrm{mm}$ transwell insert with a $5-\mu \mathrm{m}$ pore size (Corning, Wiesbaden, Germany). DMEM complete supplemented with $50 \mathrm{nM}$ 2-MeSADP (Bio-Techne, Wiesbaden, Germany) was used as a chemoattractant in the lower chamber of the transwell. Migration was assessed after $16 \mathrm{~h}$ as described before. For migration experiments with dying tumor cells $2 \times 10^{4}$ B16F1 melanoma cells were seeded in 24-well plates and cell death was induced with $2 \mu \mathrm{g} / \mathrm{mL}$ puromycin for $24 \mathrm{~h}$. Transwell inserts loaded with $5 \times 10^{5}$ transgenic Raw 264.7 cells in $100 \mu \mathrm{L}$ DMEM were added to the 24-well plate containing the puromycin-treated B16F1 cells. Untreated B16F1 cells and medium only served as controls. Either $1 \mathrm{U} / \mathrm{mL}$ apyrase was added to the puromycin-treated B16F1 cells or transgenic Raw 264.7 cells were pre-treated with $10 \mu \mathrm{M}$ of the P2Y12 antagonists PSB0739 and cangrelor (both from BioTechne, Wiesbaden, Germany). For distinct experiments, ADP (Sigma-Aldrich, Munich, Germany) instead of 2-MeSADP was added to the lower chamber of the transwell. Migration was assessed after $6 \mathrm{~h}$ as described before.

\section{ADP assay}

In all, $2 \times 10^{4}$ B16F1 melanoma cells were seeded in 24well plates and cell death was induced with $2 \mu \mathrm{g} / \mathrm{mL}$ puromycin for $24 \mathrm{~h}$. Cell supernatants were harvested and ADP concentration was determined using ADP Assay Kit (Sigma-Aldrich, Munich, Germany).

\section{Statistics}

Statistical analyses of all data were calculated by using GraphPad Prism 6.0 (GraphPad Software, USA). Statistical significance was assessed by using Student's $t$-test or by one-way ANOVA and Bonferroni as a post-test. The level of significance is indicated by asterisks $\left(^{* * * * *} \leq 0.001\right.$; $* * 0.01$ and $* 0.05)$. Error bars depict standard error of mean (SEM) of each experiment. All experiments were performed at least in triplicates.

\section{Acknowledgements \\ We thank Sayran Arif-Said, Hilltrud Schönhaber, and Jochen Weber for excellent technical assistance. This work was funded by the Deutsche Forschungsgemeinschaft (DFG, German Research Foundation) - Project number 259332240/RTG 2099}

\section{Author details}

${ }^{1}$ Department of Dermatology, Venereology and Allergology, University Medical Center and Medical Faculty Mannheim, University of Heidelberg, Mannheim, Germany. ${ }^{2}$ Center for Medical Research, Medical Faculty Mannheim, University of Heidelberg, Mannheim, Germany. ${ }^{3}$ Skin Cancer Unit, German Cancer Research Center (DKFZ), Heidelberg, Germany

Conflict of interest

The authors declare that they have no conflict of interest. 


\section{Publisher's note}

Springer Nature remains neutral with regard to jurisdictional claims in published maps and institutional affiliations.

Supplementary Information accompanies this paper at (https://doi.org/ 10.1038/s41419-019-2010-6).

Received: 6 May 2019 Revised: 2 September 2019 Accepted: 23 September 2019

Published online: 07 October 2019

\section{References}

1. Gajewski, T. F., Schreiber, H. \& Fu, Y. X. Innate and adaptive immune cells in the tumor microenvironment. Nat. Immunol. 14, 1014-1022 (2013).

2. Falleni, M. et al. M1 and M2 macrophages' clinicopathological significance in cutaneous melanoma. Melanoma Res. 27, 200-210 (2017).

3. Biswas, S. K., Chittezhath, M., Shalova, I. N. \& Lim, J. Y. Macrophage polarization and plasticity in health and disease. Immunol. Res. 53, 11-24 (2012).

4. Mills, C. D., Kincaid, K., Alt, J. M., Heilman, M. J. \& Hill, A. M. M-1/M-2 macrophages and the Th1/Th2 paradigm. J. Immunol. 164, 6166-6173 (2000).

5. Schmieder, A., Michel, J., Schönhaar, K., Goerdt, S. \& Schledzewski, K. Differentiation and gene expression profile of tumor-associated macrophages. Semin. Cancer Biol. 22, 289-297 (2012).

6. Biswas, S. K., Allavena, P. \& Mantovani, A. Tumor-associated macrophages: functional diversity, clinical significance, and open questions. Semin. Immunopathol. 35, 585-600 (2013).

7. Gabrilovich, D. I., Ostrand-Rosenberg, S. \& Bronte, V. Coordinated regulation of myeloid cells by tumours. Nat. Rev. Immunol. 12, 253-268 (2012).

8. Ostrand-Rosenberg, S., Sinha, P., Beury, D. W. \& Clements, V. K. Cross-talk between myeloid-derived suppressor cells (MDSC), macrophages, and dendritic cells enhances tumor-induced immune suppression. Semin. Cancer Biol. 22, 275-281 (2012).

9. Cassetta, L. \& Pollard, J. W. Targeting macrophages: therapeutic approaches in cancer. Nat. Rev. Drug Discov. https://doi.org/10.1038/nrd.2018.169 (2018).

10. Soulet, $\mathrm{C}$. et al. Gi-dependent and -independent mechanisms downstream of the P2Y12 ADP-receptor. J. Thrombosis Haemost. 2, 135-146 (2004).

11. Cattaneo, M. P2Y12 receptors: structure and function. J. Thromb. Haemost. 13 S10-16 (2015).

12. Haynes, S. E. et al. The P2Y12 receptor regulates microglial activation by extracellular nucleotides. Nat. Neurosci. 9, 1512-1519 (2006).

13. Ben Addi, A., Cammarata, D., Conley, P. B., Boeynaems, J. M. \& Robaye, B. Role of the $\mathrm{P} 2 \mathrm{Y} 12$ receptor in the modulation of murine dendritic cell function by ADP. J. Immunol. 185, 5900-5906 (2010).

14. Muniz, V. S. et al. Purinergic P2Y12 receptor activation in eosinophils and the schistosomal host response. PLOS ONE 10, e0139805 (2015)

15. Paruchuri, S. et al. Leukotriene E4-induced pulmonary inflammation is mediated by the P2Y12 receptor. J. Exp. Med. 206, 2543-2555 (2009).

16. Kaufmann, C. C., Lyon, A. R., Wojta, J. \& Huber, K. Is P2Y12 inhibitor therapy associated with an increased risk of cancer? Eur. Heart J. Cardiovasc. Pharmacother. 5, 100-104 (2019).

17. Kotronias, R. A. et al. Cancer event rate and mortality with thienopyridines: a systematic review and meta-analysis. Drug Saf. 40, 229-240 (2017).

18. Leader, A. et al. The effect of combined aspirin and clopidogrel treatment on cancer incidence. Am. J. Med. 130, 826-832 (2017).

19. $\mathrm{Xu}$, J. et al. GPR105 ablation prevents inflammation and improves insulin sensitivity in mice with diet-induced obesity. J. Immunol. 189, 1992-1999 (2012).

20. Mildner, A., Huang, H., Radke, J., Stenzel, W. \& Priller, J. P2Y12 receptor is expressed on human microglia under physiological conditions throughout development and is sensitive to neuroinflammatory diseases. Glia 65, 375-387 (2017).

21. Dollt, $\mathrm{C}$. et al. The shedded ectodomain of Lyve-1 expressed on M2-like tumor-associated macrophages inhibits melanoma cell proliferation. Oncotarget 8, 103682-103692 (2017).

22. Dorsam, R. T. \& Kunapuli, S. P. Central role of the P2Y12 receptor in platelet activation. J. Clin. Investig. 113, 340-345 (2004).

23. Vogel, D. Y. et al. Human macrophage polarization in vitro: maturation and activation methods compared. Immunobiology 219, 695-703 (2014).

24. Taves, M. D., Gomez-Sanchez, C. E. \& Soma, K. K. Extra-adrenal glucocorticoids and mineralocorticoids: evidence for local synthesis, regulation, and function. Am. J. Physiol. Endocrinol. Metab. 301, E11-24 (2011).

25. Tozaki-Saitoh, $H$. et al. P2Y12 receptors in primary microglia activate nuclear factor of activated T-cell signaling to induce C-C chemokine 3 expression. J. Neurochem. 141, 100-110 (2017).

26. Gelosa, P. et al. Microglia is a key player in the reduction of stroke damage promoted by the new antithrombotic agent ticagrelor. J. Cereb. Blood Flow. Metab. 34, 979-988 (2014).

27. Hardy, A. R. Reciprocal cross-talk between P2Y1 and P2Y12 receptors at the level of calcium signaling in human platelets. Blood 104, 1745-1752 (2004).

28. Ohsawa, $\mathrm{K}$. et al. Involvement of P2X4 and P2Y12 receptors in ATP-induced microglial chemotaxis. Glia 55, 604-616 (2007).

29. Suh, D. H. et al. P2Y12 antagonist attenuates eosinophilic inflammation and airway hyperresponsiveness in a mouse model of asthma. J. Cell. Mol. Med. 20, 333-341 (2016).

30. Ganbaatar, B. et al. Ticagrelor, a P2Y12 antagonist, attenuates vascular dysfunction and inhibits atherogenesis in apolipoprotein-E-deficient mice. Atherosclerosis 275, 124-132 (2018).

31. De Simone, R. et al. TGF- $\beta$ and LPS modulate ADP-induced migration of microglial cells through $\mathrm{P} 2 \mathrm{Y} 1$ and $\mathrm{P} 2 \mathrm{Y} 12$ receptor expression. J. Neurochem. 115, 450-459 (2010).

32. Moore, C. S. et al. P2Y12 expression and function in alternatively activated human microglia. Neurol. Neuroimmunol. Neuroinflamm. 2, e80 (2015).

33. Junger, W. G. Immune cell regulation by autocrine purinergic signalling. Nat Rev. Immunol. 11, 201-212 (2011).

34. Zhang, $X$. et al. Extracellular ADP facilitates monocyte recruitment in bacterial infection via ERK signaling. Cell. Mol. Immunol. 15, 58-73 (2018).

35. Kawamura, H., Kawamura, T., Kanda, Y., Kobayashi, T. \& Abo, T. Extracellular ATP-stimulated macrophages produce macrophage inflammatory protein2 which is important for neutrophil migration. Immunology 136, 448-458 (2012).

36. Ben Yebdri, F., Kukulski, F., Tremblay, A. \& Sevigny, J. Concomitant activation of $\mathrm{P} 2 \mathrm{Y}(2)$ and $\mathrm{P} 2 \mathrm{Y}(6)$ receptors on monocytes is required for TLR1/2-induced neutrophil migration by regulating $\mid \mathrm{L}-8$ secretion. Eur. J. Immunol. 39, 2885-2894 (2009)

37. Cekic, C. \& Linden, J. Purinergic regulation of the immune system. Nat. Rev. Immunol. 16, 177-192 (2016).

38. Elliott, M. R. et al. Nucleotides released by apoptotic cells act as a find-me signal to promote phagocytic clearance. Nature 461, 282-286 (2009).

39. Cho, M. S. et al. Role of ADP receptors on platelets in the growth of ovarian cancer. Blood 130, 1235-1242 (2017)

40. Wang, Y. et al. Platelet P2Y12 is involved in murine pulmonary metastasis. PLoS One 8, e80780 (2013)

41. Gebremeskel, S., LeVatte, T., Liwski, R. S., Johnston, B. \& Bezuhly, M. The reversible $\mathrm{P} 2 \mathrm{Y} 12$ inhibitor ticagrelor inhibits metastasis and improves survival in mouse models of cancer. Int. J. Cancer 136, 234-240 (2015).

42. Dai, M. et al. Evolving gene/transcript definitions significantly alter the interpretation of GeneChip data. Nucleic Acids Res. 33, e175 (2005).

43. Subramanian, A. et al. Gene set enrichment analysis: a knowledge-based approach for interpreting genome-wide expression profiles. Proc. Natl Acad. Sci. USA 102, 15545-15550 (2005). 